\title{
Executive Summary: Understanding the lives of adolescents and young adults (UDAYA) in Uttar Pradesh, India (2015-16)
}

\author{
K.G. Santhya \\ Population Council \\ Rajib Acharya \\ Population Council \\ Neelanjana Pandey \\ Population Council \\ Ashish Kumar Gupta \\ Population Council \\ Shilpi Rampal \\ Population Council
}

See next page for additional authors

Follow this and additional works at: https://knowledgecommons.popcouncil.org/departments_sbsr-pgy

Part of the Demography, Population, and Ecology Commons, Family, Life Course, and Society Commons, International Public Health Commons, and the Maternal and Child Health Commons How does access to this work benefit you? Let us know!

\section{Recommended Citation}

Santhya, K.G., Rajib Acharya, Neelanjana Pandey, Ashish Kumar Gupta, Shilpi Rampal, Santosh Kumar Singh, and A.J. Francis Zavier. 2017. "Executive Summary: Understanding the lives of adolescents and young adults (UDAYA) in Uttar Pradesh, India (2015-16)." New Delhi: Population Council. 


\section{Authors}

K.G. Santhya, Rajib Acharya, Neelanjana Pandey, Ashish Kumar Gupta, Shilpi Rampal, Santosh Kumar Singh, and A.J. Francis Zavier

This report is available at Knowledge Commons: https://knowledgecommons.popcouncil.org/departments_sbsr-pgy/ 


\section{POPULATION COUNCIL}

Ideas. Evidence. Impact.

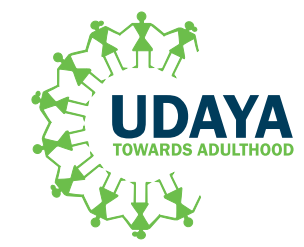

Understanding the lives of adolescents and young adults (UDAYA) in Uttar Pradesh, India

(2015-16)
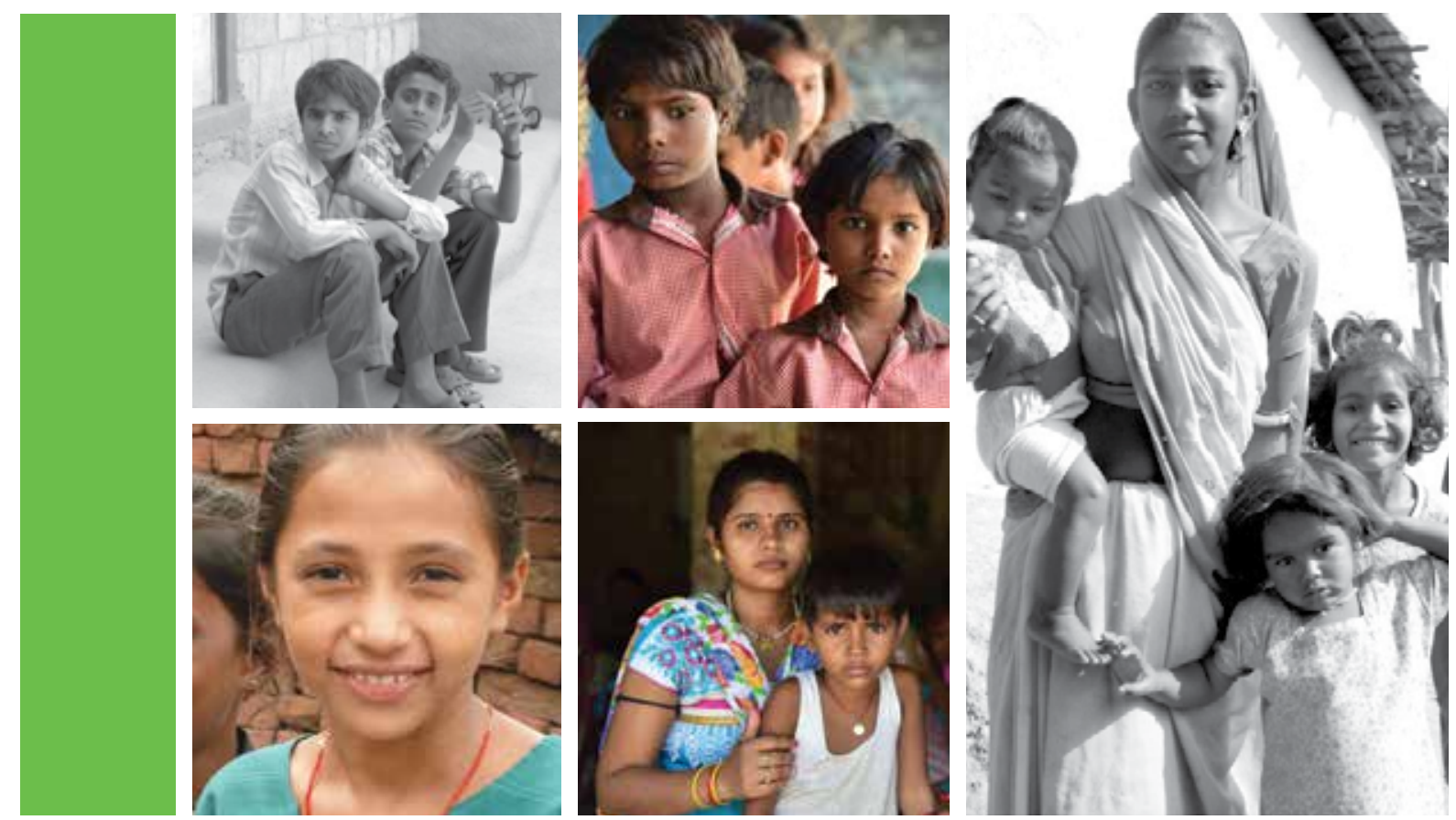

\section{Executive Summary}




\section{POPULATION}

COUNCIL

Ideas. Evidence. Impact.

The Population Council confronts critical health and development issues-from stopping the spread of HIV to improving reproductive health and ensuring that young people lead full and productive lives. Through biomedical, social science, and public health research in 50 countries, we work with our partners to deliver solutions that lead to more effective policies, programs, and technologies that improve lives around the world. Established in1952 and headquartered in New York, the Council is a nongovernmental, nonprofit organization governed by an international board of trustees.

For additional copies, please contact:

Population Council

Zone 5A, Ground Floor

India Habitat Centre, Lodi Road

New Delhi, India 110003

Phone: 91-11-24642901

Email: info.india@popcouncil.org

Website: www.popcouncil.org

\section{Suggested citation:}

Santhya, K. G., R. Acharya, N. Pandey et al. 2017. Understanding the lives of adolescents and young adults (UDAYA) in Uttar Pradesh, India. Executive Summary. New Delhi: Population Council.

\section{Authors' contributions:}

K G Santhya conceptualized the study, participated in its design and implementation, guided data analysis, wrote the report, and made critical revisions and finalized the report. Rajib Acharya conceptualised the study, participated in its design and implementation, contributed to drafting the report, and conducted data analysis. Neelanjana Pandey conducted data analysis and provided technical support to field implementation. Ashish Kumar Gupta contributed to field implementation and data management, and conducted data analysis. Shilpi Rampal contributed to field implementation, data management and analysis. Santosh Singh managed field implementation and contributed to data management and analysis.

A J Francis Zavier contributed to data management.

\section{Copyright: ( 2017 The Population Council, Inc.}




\section{Understanding the lives of adolescents and young adults (UDAYA) in Uttar Pradesh, India \\ (2015-16)}

\section{Executive Summary}



Adolescents in ages 10-19 constitute one-fifth of the Indian population, and, globally, every fifth adolescent lives in India. India has articulated its commitment to protect and promote the health and rights of adolescents and meet their development needs through numerous policies and programmes, which are being implemented over the course of this century particularly. Despite these commitments, Indian adolescents and youth are, for the most part, unprepared to meet the needs of a globalising world-few complete high school, the quality of education received by many is poor, many lack livelihood skills and employment opportunities, the health of many is compromised, and gender gaps and gaps between the socio-economically disadvantaged and advantaged persist. Therefore, there is clearly a need for a commitment to ensure that promises made in policies are translated into reality for adolescents, that programmes do indeed reach adolescents, that the scope and content of the programmes are expanded, and that promising lessons are assimilated and scaled-up.

Major gaps in data on adolescents pose one of the biggest challenges in promoting their rights. The absence of longitudinal data that are essential to understand the factors that determine rather than those that are associated with healthy transitions from childhood to adolescence and adulthood and successive cross-sectional data that are important to establish the levels of key markers of these transitions at various points in time have thwarted the designing of optimal programmes as well as rigorous assessment of the reach and effectiveness of on-going programmes.

The programme of research titled, 'Understanding the lives of adolescents and young adults (UDAYA) in Bihar and Uttar Pradesh', implemented by the Population Council, seeks to fill these gaps in evidence. The goal of UDAYA is to establish the levels, patterns, and trends in the situation of younger (10-14) and older (15-19) adolescents and assess factors that influence the quality of transitions they make. The specific objectives of UDAYA are: (1) to explore the situation of adolescents, with a focus on assessing the extent to which both younger and older adolescents have acquired a set of assets that can help them make a healthy, safe, and successful transition from adolescence to young adulthood in the states of Bihar and Uttar Pradesh; (2) to describe the extent to which the situation of adolescents has changed over time; and (3) to assess factors that determine the accumulation or loss of assets and the quality of transitions from adolescence to young adulthood.

UDAYA uses both cross-sectional and longitudinal designs and focuses on unmarried boys in ages 10-14 and 15-19, unmarried girls in ages 10-14 and 15-19, and married girls in ages 15-19 in both rural and urban settings in Bihar and Uttar Pradesh. These two states together constitute 25 percent of the country's population and adolescents in these states account for 29 percent of the country's adolescent population. This report focuses on the findings from the first round of cross-sectional surveys of adolescents conducted during September 2015 and January 2016 in Uttar Pradesh. A total of 10,161 interviews were completed: 1,072 with younger boys, 2,064 with older boys, 889 with younger girls, 4,338 with unmarried older girls and 1,798 with married older girls. The survey also conducted anthropometric measurement of 3,822 adolescents and haemoglobin testing for 3,718 adolescents from among the study participants.

\section{Characteristics of the household population}

A total of 33,964 households were selected for interview; among these, interviews were successfully completed for 32,348 sample households.

Housing characteristics of the surveyed population show a mixed picture with regard to living conditions. On the whole, 17 percent of households lived in kachcha houses (constructed from mud, thatch, or other low-quality materials), 43 percent lived in semi-pucca houses (constructed using a mix of low- and high-quality materials), and 40 percent lived in pucca houses (constructed entirely from cement, masonry, or other high-quality materials). About half of residential structures contained 2-3 rooms (48\%) and over one-quarter (29\%) contained just one room. Only 58 percent of the households had electricity, and just 46 percent of households had access to a toilet facility of any kind. The main source of cooking fuel was coal, charcoal, wood, crop residue, or dung cakes, reported by 72 percent of households, and liquid petroleum gas was used, in contrast, by just 28 percent of households. However, almost all 
households (96\%) reported that their main source of drinking water was either piped water or water obtained from a hand-pump or a covered well. More than nine out of ten households reported ownership of a landline or mobile phone (92\%).

The distribution of households by wealth quintiles shows a stark divide between rural and urban areas: two-fifths $(42 \%)$ of urban households were in the wealthiest (fifth) quintile; in contrast, only one-seventh (14\%) of rural households were in this quintile. Similarly, one-quarter of rural households were in the poorest (first) quintile of the index compared with only five percent of urban households.

Findings also show that rural households' access to poverty alleviation programmes, for example, the Mahatma Gandhi National Rural Employment Guarantee Act (MNREGA), was limited. Just 12 percent of rural households had benefited from the MNREGA scheme in the year preceding the interview.

Finally, findings highlight widespread substance use among the household population, particularly the use of tobacco products: 71 percent of households contained at least one household member who consumed tobacco products; 24 percent of households contained at least one member who consumed alcohol; and three percent of households contained at least one member who consumed drugs.

\section{Situation of adolescents}

A total of 10,161 adolescents were interviewed. Age profiles among girls in ages 15-19 years show that married girls were older than their unmarried counterparts, with 80 percent of married girls compared with 33 percent of unmarried girls falling into the age group of 18-19 years. The distribution of adolescents by religion shows that 73-82 percent of adolescents were Hindu and 17-27 percent were Muslim. Caste-wise distribution shows that about half of the adolescents belonged to other backward castes (50-54\%), 23-29 percent to scheduled castes, 16-26 percent to general castes, and one percent or less to scheduled tribes. Finally, mothers of the majority of adolescents, particularly married older girls, had no formal education; mothers of 83 percent of married older girls and 66-69 percent of the other four categories of adolescents had no formal education.

\section{Education}

Findings show that school enrolment was nearly universal among adolescents, except for married older girls, among whom a considerable proportion of married girls-one out of five-were never enrolled in school. Findings highlight, moreover, that differences by sex in school enrolment had disappeared and that differences between adolescents of rural and those of urban areas were modest.

Although school enrolment was nearly universal, attainment of educational milestones was far from satisfactory. Data presented in Figure 1 show that specifically, among those in ages 10-14, just 62 percent and 65 percent of boys and girls, respectively, had completed five years or more of schooling. Likewise, among adolescents in ages 15-19 years, excluding married girls, 77 percent and 74 percent of boys and girls, respectively, had completed eight years or more of schooling. Finally, among adolescents in ages 18-19 years, excluding married girls, 59 percent and 62 percent of boys and girls, respectively, had completed 10 years or more of schooling. Differences by sex and differences between adolescents from rural and those from urban areas in the attainment of selected educational milestones were muted for the most part. Moreover, several sub-groups of adolescents were particularly disadvantaged-married older girls, Muslim adolescents, those belonging to scheduled castes, those belonging to poor households, and those most likely to be first-generation learners-as measured by mother's educational attainment. 
Figure 1: Percentage of adolescents who had achieved selected education millestones, Uttar Pradesh, 2015-16

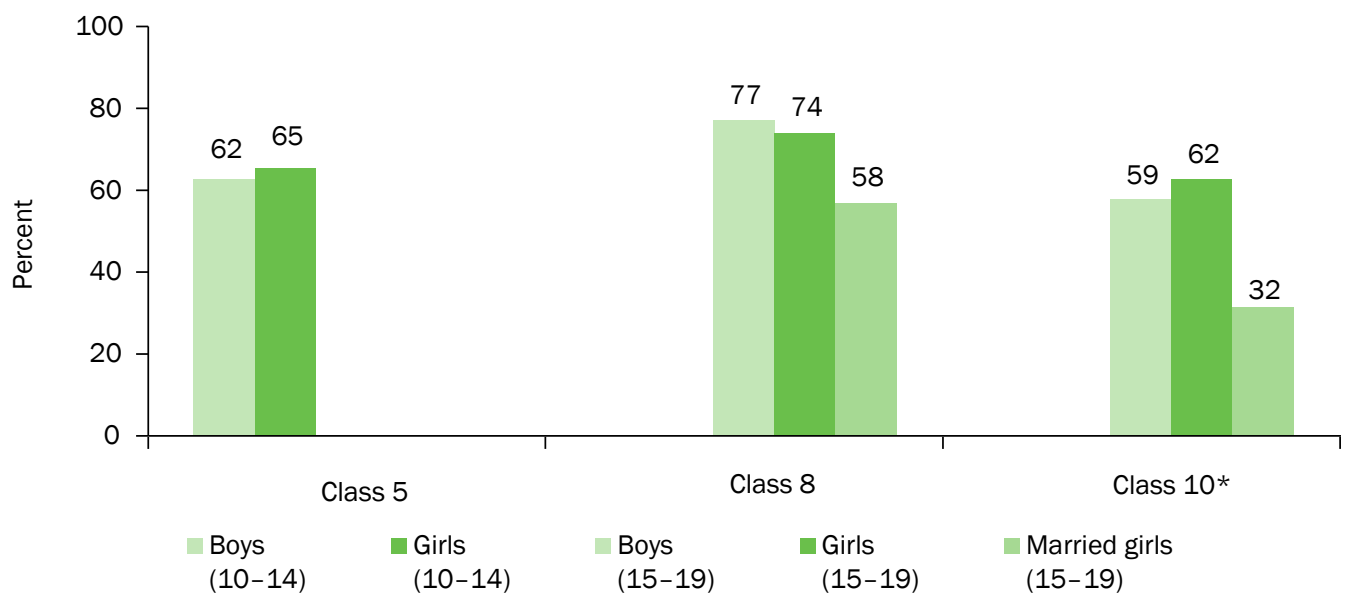

Note: ${ }^{\star}$ Adolescents in ages $18-19$ years.

Retention in school was far from universal even among younger adolescents despite the introduction of the Right to Education Act, 2009, that has made primary education free and compulsory, with 86-91 percent of younger adolescents, 52-63 percent of older boys and unmarried older girls, and five percent of married older girls were enrolled in a school or college at the time of the interview. Furthermore, school retention declined steadily as boys and girls transitioned from early adolescence to late adolescence, with steeper declines among girls than boys and among married than unmarried older girls. While 90-93 percent of boys and unmarried older girls in ages 15-19 were in school at age 10, just 69-78 percent were in school at age 15 (Figure 2).

\section{Figure 2: Percentage of adolescents in ages 15-19 who were in school at the ages 10, 12, and 15,* Uttar} Pradesh, 2015-16

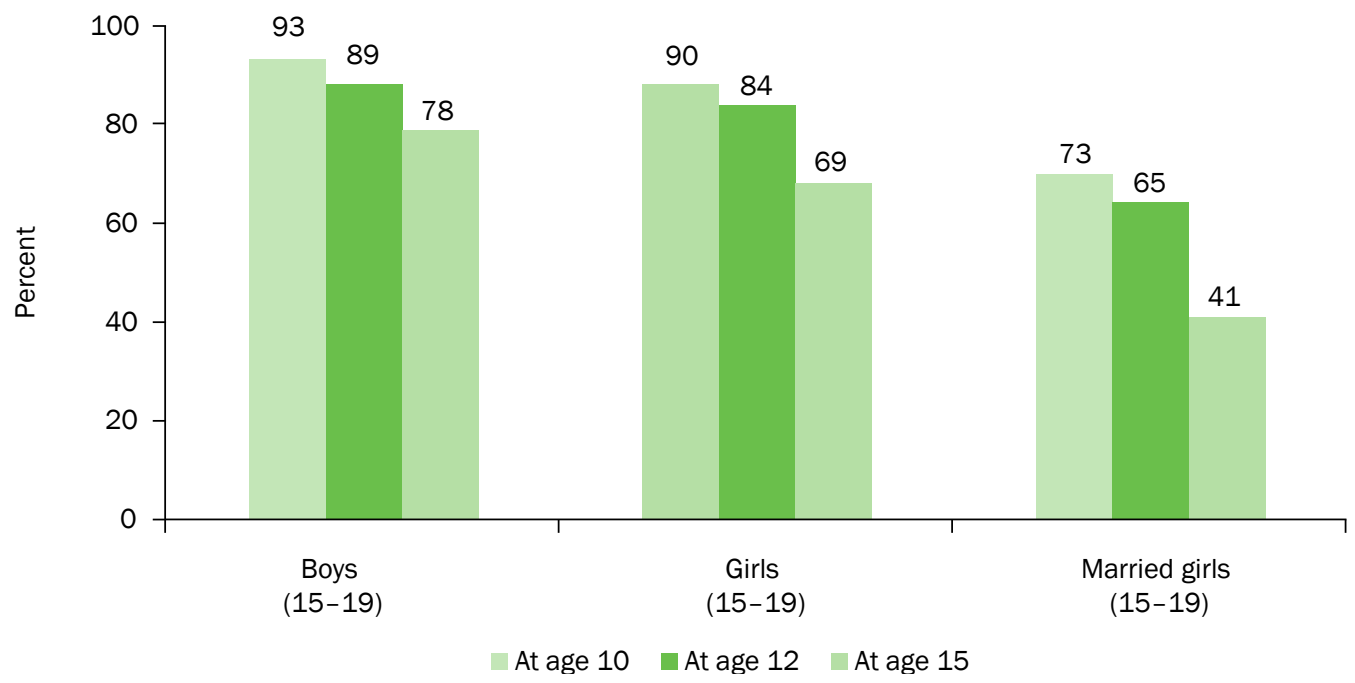

Note: *Includes those who were pursuing their education through distance education programmes.

Among adolescents in ages of 15-19 who had completed at least one year of schooling, major declines in school completion levels occurred between Classes 5 and 6. Classes 8 and 9, and Classes 12 and 13 in both rural and urban areas. While declines in school completion levels between these classes did not differ between boys and girls, for the most part, it was much steeper among married than unmarried older girls. 
The leading reason for never enrolling in school among older adolescents was attitude- or perception-related (unsafe to send children to school, education not considered necessary by respondent or parents, respondent's lack of interest), as reported by 56 percent of boys and 54-58 percent of girls. While the respondent's lack of interest predominated among attitude- or perception-related reasons among boys, parental perceptions that education is not necessary predominated among girls. The second most commonly cited reason was economic, particularly that the family could not afford to keep the respondent in school, as reported by 38 percent of boys and 32-36 percent of girls. Notable proportions of adolescents, particularly older girls, regardless of marital status, attributed their nonenrolment in school to housework-related reasons.

Among older adolescents who were enrolled in school, differences by sex in reasons for discontinuation before completing Class 12 were apparent. As with never enrolling in school, the most frequently cited reason for school discontinuation was related to attitudes and perceptions for all categories of adolescents-reported by 54 percent of boys and 39-42 percent of girls. The leading attitude- or perception-related reasons were the respondent's lack of interest in studies among boys and parental perceptions that education is not necessary among girls. Other reasons for discontinuation were economic constraints, reported by 43 percent of boys and 18-28 percent of girls, and housework-related reasons, mentioned by 21-25 percent of girls. While boys were equally likely to cite work on the family farm or business, wage-earning work, and family poverty, girls cited primarily family poverty. Findings also show that girls were more likely than boys to attribute their school discontinuation to school-related reasons (19-28\% versus $12 \%$ ). Among school-related reasons, the poor quality of facilities and teaching predominated among boys, while the distant location of the school and the non-availability of transportation featured primarily among girls. One in five married girls reported that they had discontinued their education because they had got engaged or married. Findings also show that concerns about girls' safety or experience of menstruation were rarely cited as a reason for school discontinuation.

Differences by sex were apparent with regard to the type of educational facility in which adolescents were enrolled at the time of the interview or at the time of discontinuing their education. Boys were more likely than girls to be enrolled in a private educational facility (63\% versus $52 \%$ among younger adolescents; $55 \%$ versus $36-46 \%$ among all older adolescents). Younger adolescents (but not older adolescents) in urban areas were more likely than their rural counterparts to be enrolled in a private educational institution. Enrolment in private educational institutions was positively associated with caste, household wealth index, current school enrolment, and mother's educational attainment.

Almost all adolescents, irrespective of age, sex, and rural or urban residence, reported access to drinking water in schools and considerable majorities to playgrounds. Toilets in working condition and library facilities were less likely to be reported by adolescents. The availability of all four amenities-drinking water, playgrounds, toilets, and librarieswas reported by just one-fifth to one-third of boys and one-third to two-fifths of girls. Somewhat larger percentages of adolescent girls than boys reported the availability of all four amenities, which was most likely because the presence of these amenities was considered a prerequisite for girls' enrolment in school. The availability of all four amenities was more likely to be reported by those who were pursuing their education at the time of interview than those who had discontinued their education. Interestingly, the availability of all four amenities did not differ by the type of educational institution in which adolescents were enrolled at the time of the interview or at the time of discontinuing their education for the most part (Figure 3).

Schooling experiences among those who were pursuing their education at the time of the interview were characterised by absenteeism and reliance on private tuition for many. Regular attendance, as defined by attending all six school days in the week prior to the interview, was reported by half to two-thirds of boys and one-third to two-thirds of girls. Regular attendance was more likely to be reported by younger than older adolescents, and by unmarried than married older girls. Differences by sex were evident in leading reasons for absenteeism. Economic reasons, namely, their having to work on the family farm or business or for pay, and health-related reasons topped the list of reasons among younger boys (28-29\%), and economic reasons topped the list among older boys (35\%). In contrast, reasons related to housework or to a family function, but particularly housework, topped the list of reasons among all categories of girls (38\% of younger girls, $31 \%$ of unmarried older girls, and $39 \%$ of married older girls). 
A notable proportion of adolescents who were pursuing their education at the time of the interview, particularly boys and those from urban areas, reported that they had taken private tuition in the month prior to the interview-onequarter to two-fifths of boys and one-tenth to one-quarter of girls. Taking private tuition was more common among urban than rural adolescents, Hindu adolescents than Muslim adolescents, those belonging to general castes than other castes, those from economically better-off households than poorer households, and those whose mother was well educated than those whose mother was less educated. Interestingly, the practice of taking private tuition did not differ, by and large, by the type of educational institution respondents had enrolled at the time of the interview. Finally, 19-21 percent of boys and 8-18 percent of girls had served as a prefect or monitor in the class in which they were currently attending or had last attended.

Of older adolescents who were never enrolled in school, one-fifth of older boys and married older girls and one-third of unmarried older girls expressed a desire to enrol in school. Among adolescents who had discontinued their education before completing Class 12, a substantial proportion expressed a desire to return to school-one-quarter of boys and one-quarter to two-fifths of girls. Furthermore, the vast majority of younger and older adolescents who were currently pursuing their education in a school/college aspired to complete at least senior secondary education/college (Classes 12 and above)-three-quarters of younger adolescents and over nine-tenths of older adolescents, regardless of sex and place of residence, aspired to do so.

Most adolescents who were enrolled at the time of the interview or in the year preceding the interview in a class whose students were eligible for entitlements from their school were aware of these entitlements. Specifically, 95-98 percent of boys and 98-99 percent of girls were aware that students are entitled to receive free uniforms and textbooks; 94 percent of older boys and 98-99 percent of unmarried and married older girls were aware of scholarships. The extent to which adolescents had benefited from the entitlements was lower than the levels of their awareness of these entitlements. Among adolescents who were currently enrolled in classes whose students were eligible to claim entitlements, $64-80$ percent of boys and $77-85$ percent of girls reported that they had received the midday meal on the last day that she/he had attended school. Among adolescents who were enrolled in classes eligible for the entitlements at the time of the interview or in the year preceding the interview, 57-78 percent of boys and 79-89 percent of girls had received free uniforms or money to buy uniforms in the year preceding the interview. A slightly larger proportion of adolescents-74-87 percent of boys and 86-92 percent of girls-had received free textbooks or money to buy textbooks in the year preceding the interview. Few-20-32 percent of boys and 23-41 percent of girls-had received a scholarship in the year preceding the interview. Rural adolescents were more likely than their urban counterparts to have received the midday meal and free uniforms and textbooks. Finally, one percent of older boys, three percent of unmarried older girls, and less than one percent of married older girls who had passed out of Classes 10 or 12 in the year preceding the interview reported that they had received a tablet or laptop.

Findings show that 15 percent of boys and 28-30 percent of younger girls and unmarried older girls who were enrolled in classes whose students were eligible to participate in the Meena Manch programme at the time of the interview or in the year preceding the interview had heard about this programme. However, participation in the activities of the programme was reported by just seven percent each of younger boys, younger girls, and unmarried older girls, and two percent of older boys.

Findings highlight poor learning levels among adolescents: between one-half and three-quarters of adolescents were able to read a Class 2 text fluently in Hindi. While differences by sex were mild, more of older than younger adolescents, more of unmarried than married older girls, and more of urban than rural adolescents were able to read fluently. Numeracy levels were also poor-between 10 percent and 46 percent of adolescents only were able to solve a simple division problem. A larger proportion of boys than girls were able to solve a division problem as were unmarried older girls compared with married older girls and urban adolescents compared with rural adolescents. Some 35 percent of younger boys and 44 percent of older boys were thus literate and numerate as were 22 percent of younger girls, 26 percent of unmarried older girls, and nine percent of married older girls were both literate and numerate (Figure 3). 
Figure 3: Percentage of adolescents who could read a Class 2 text fluently in Hindi and solve a simple division problem,* Uttar Pradesh, 2015-16

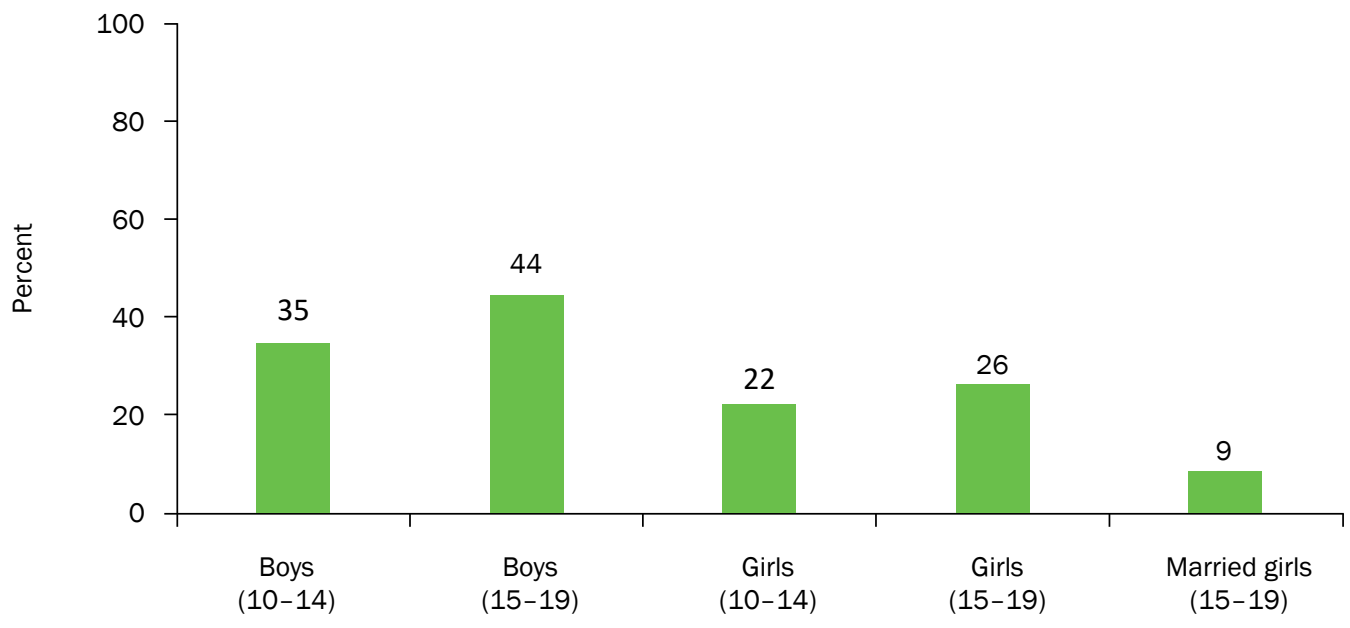

Note: * Of those who were ever enrolled in school.

It is notable that even among those who had completed primary education (that is, Class 8 or more), not all could read a Class 2 text fluently or solve a division problem. Literacy and numeracy skills were particularly poor among several sub-groups of adolescents-those belonging to scheduled castes, those belonging to poor households, those who had discontinued their education, those who had attended government educational institutions, and those who were first-generation learners. Findings also highlight that adolescents tend to lose literacy and numeracy skills over time; at the same level of years of schooling completed, younger adolescents were more likely than older adolescents to read a Class 2 text fluently and solve a division problem, which is, perhaps, a reflection of rote learning in schools.

\section{Work}

Work profiles suggest that almost three-fifths of younger boys and over four-fifths of older boys had at some time engaged in paid or unpaid work; fewer girls-one-third of younger girls and half of unmarried and married older girlshad done so. Moreover, adolescents were far more likely to have engaged in unpaid than paid work. Paid work was initiated in childhood or early adolescence, that is, before age 14, for as many as 10-16 percent of adolescents. Data on work participation in the 12 months prior to interview largely mirrored lifetime economic activity for all categories of adolescents, except for married older girls, among whom fewer reported economic activity in the last 12 months than over the course of the life. Among adolescents who worked for remuneration in the year prior to the interview, only a few had worked full time, that is, six months or more-14-18 percent of younger adolescents and 28-39 percent of older adolescents. Occupational profiles among those working for wages in the 12 months preceding the interview show that agricultural labour and unskilled non-agricultural labour were the leading occupations among younger and older adolescents, followed, among older adolescents, by skilled labour.

Findings also suggest that a substantial proportion of older adolescents, particularly boys, were in search of paid employment at the time of the interview-32 percent of boys and 11-12 percent of girls. Adolescents who had completed 12 or more years of schooling were more likely than those with fewer years of schooling to be actively seeking paid employment-56 percent compared with 25-40 percent among boys and 24-27 percent compared with 6-12 percent among girls.

A large proportion of older adolescents who were actively seeking paid employment at the time of the interview preferred to work in the government sector-55 percent of boys and 44-56 percent of girls (Figure 4). In contrast, just 12 percent of boys and 5-6 percent of girls expressed a preference to work in the private sector, and eight percent of boys and 13-27 percent of girls were willing to work in either sector. Some 22 percent of boys and 15-19 percent of girls reported that they would prefer to take up self-employment (Figure 4). Leading reasons for preferring a government sector job were perceptions of financial security (higher salary, regular payment, provision of pension and increment), job security, normative preference, and perceptions that workload is less in the government sector. 


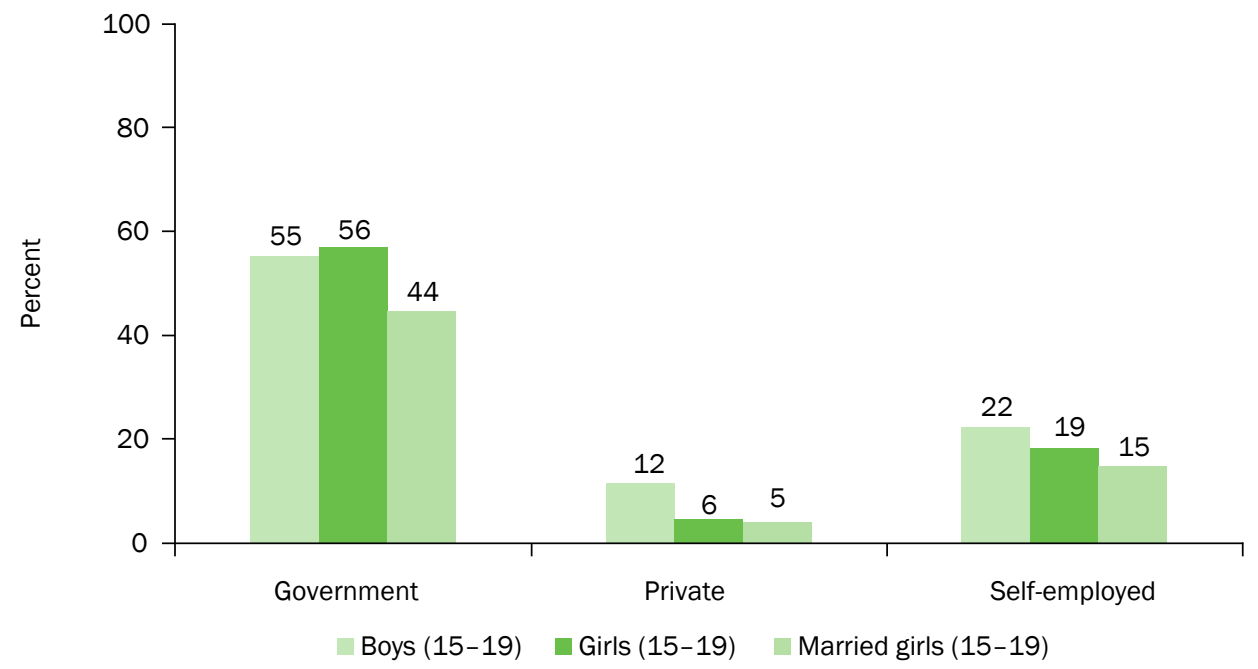

Note: ${ }^{\star}$ Of those who were actively seeking paid employment at the time of the interview.

Data on activity status during adolescence among older adolescents show that school enrolment declined across all groups as they transitioned out of early adolescence into late adolescence-from 93 percent to 78 percent among older boys and from 90 percent to 69 percent among unmarried girls at the ages of 10 and 15, respectively (Figure 5.5a-5.5c). Such declines took place earlier among married girls than boys and unmarried girls. The exit from school was accompanied by a steady rise in work participation as age increased among older boys, but with a much more gradual rise for unmarried girls. However, a different pattern was observed for married girls, among whom work participation increased gradually till age 16 and thereafter started declining, perhaps coinciding with their transition to marriage and motherhood. A large proportion of boys had combined studying and working, which increased from one in four at age 10 to one in two at ages 14-17. Fewer girls, particularly the married, had done so. Significant proportions of girls, particularly married girls, were neither in school nor working from age 10 onwards, which, among unmarried girls, increased from nine percent to 20 percent, and, among married girls, from 20 percent to 68 percent at the ages of 10 and 19, respectively. In contrast, six percent or fewer boys were neither working nor in school at any age.

Figure 5a: Activity status among adolescent boys in ages 15-19, by age, Uttar Pradesh, 2015-16

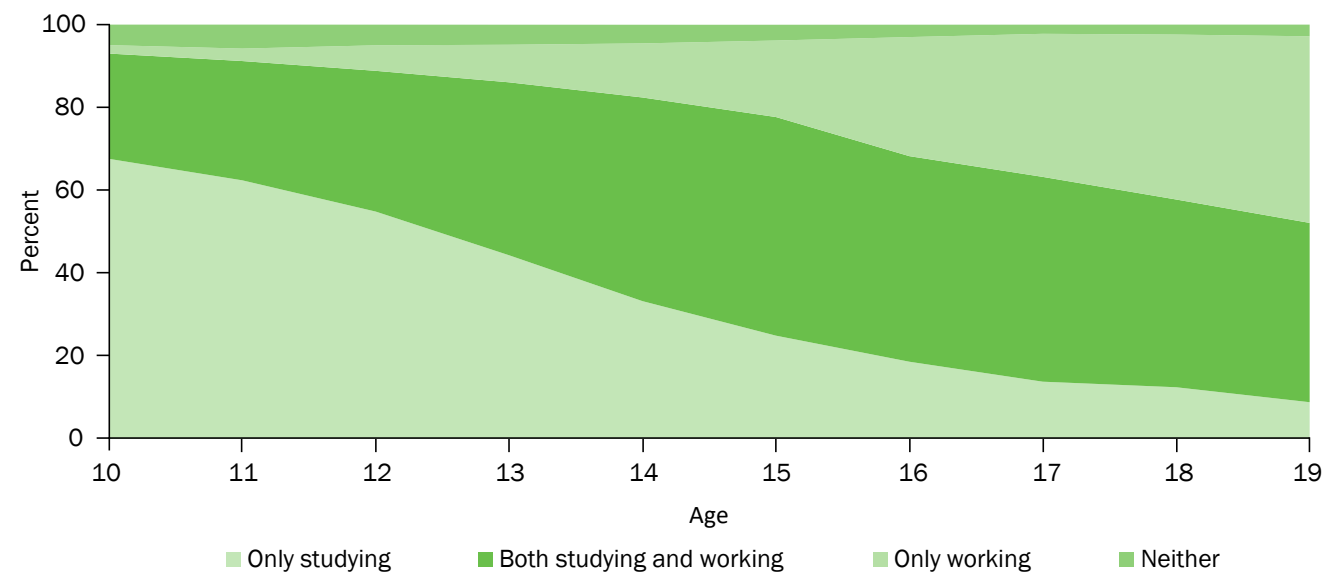


Figure 5b: Activity status among unmarried girls in ages 15-19, by age, Uttar Pradesh, 2015-16

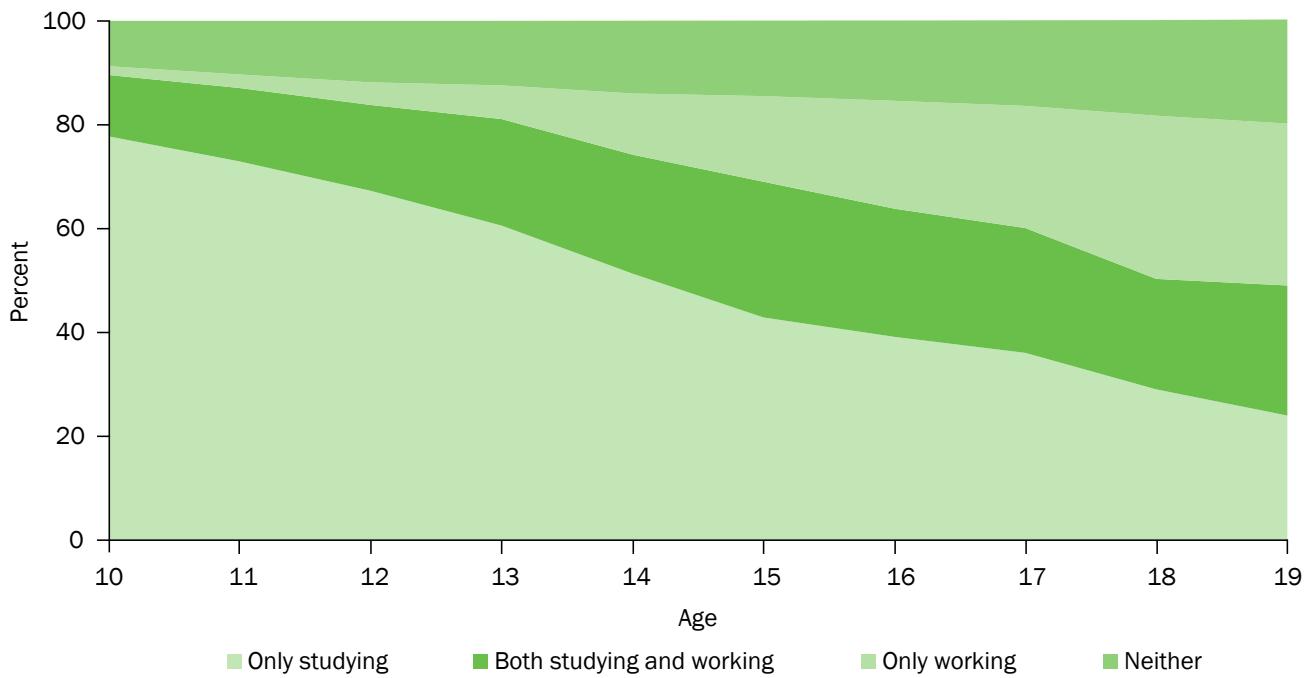

Figure 5c: Activity status among married girls in ages 15-19, by age, Uttar Pradesh, 2015-16

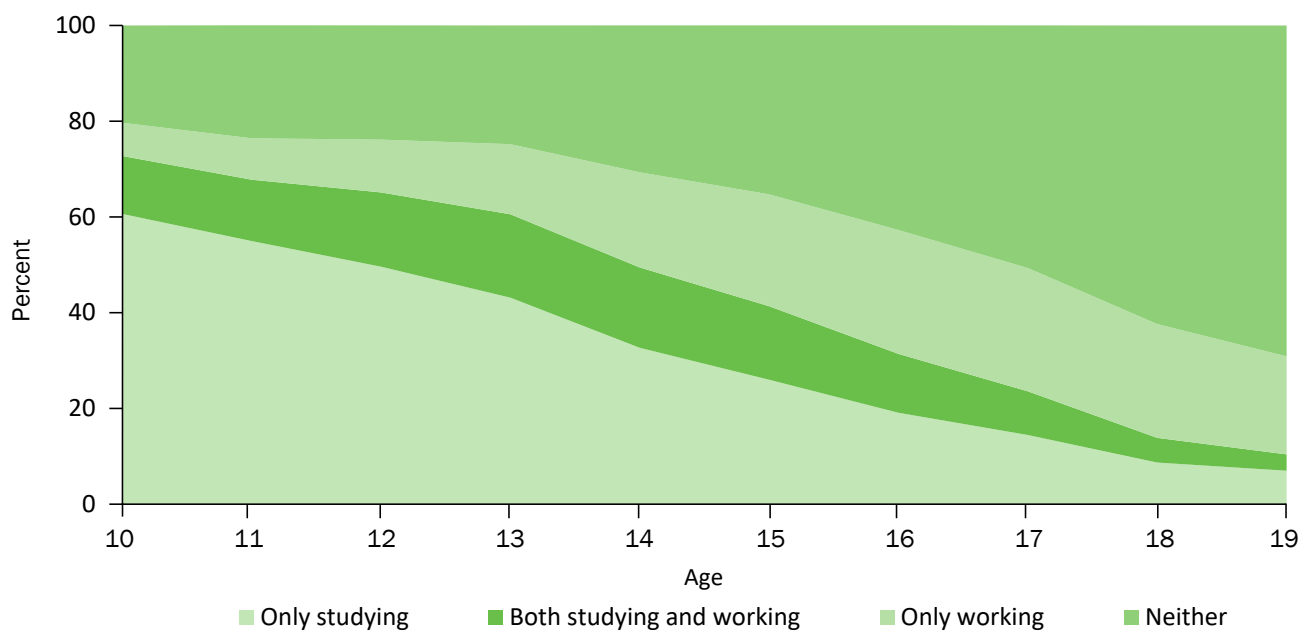

Only a few older adolescents had ever attended a formal vocational training programme-six percent of boys and 12-15 percent of unmarried and married girls. Even fewer (4-8\%) had attended a formal vocational training programme in the year preceding the interview. The kind of training received by older adolescents who had attended a vocational training programme in the year preceding the interview varied widely by sex of the respondent and rural or urban residence. Among boys, leading programmes attended were computer training (62\%) and auto mechanics or electrical work (15\%). Among girls, the leading programme was tailoring for both unmarried and married girls. However, we observed differences in key vocational training received by unmarried and married girls. Among unmarried girls, the most commonly reported training programmes undertaken were tailoring (68\%), followed by computer training (12\%) and beauty parlour skills (9\%), and among married girls, the leading programme was tailoring, as reported by 83 percent, with very few opting for skills training in other vocations. A large proportion of adolescents who had attended a formal vocational training programme had attended the programme in a private institution-67 percent of boys and 59-62 percent of unmarried and married girls. Of those adolescents who had attended a formal vocational training programme in the year preceding the interview, two-fifths, regardless of sex and, among girls, of marital status, had completed the course/s attended. Of those who had completed a vocational training course in the year prior to the interview, a larger proportion of boys than girls received a certificate upon the completion of the training course (57\% versus $35-49 \%)$. The vast majority of those who had completed the training course reported that they felt competent to use the skill acquired-90 percent of boys and 71-85 percent of girls. Far fewer reported that they got employment in the same trade after completing the course -13 percent of boys and 
25-26 percent of unmarried and married girls; differences by sex in securing employment in the same trade after completing the course may be attributed to the differences in the trade in which boys and girls were trained, for example, computer training among boys and tailoring among girls.

On the whole, large proportions of adolescents-76 percent of boys and 74-87 percent of girls-reported interest in attending vocational training programmes. Several, moreover, expressed an unmet need for acquiring skills that would enable employment generation. Some 11 percent of boys and 29-34 percent of girls noted that they had at some point wanted to attend a course but could not do so. The leading reasons for their not being able to attend the course across all categories of adolescents were related to demand-side issues, as cited by 77 percent of boys and 75-82 percent of girls with an unmet need. Leading among the demand-side reasons were lack of affordability of costs for the course, lack of time, including that of the course timing clashing with studies and housework-related responsibilities, and family members' objections. Some 26 percent of boys and 29-38 percent of girls reported at least one supply-side-related reason for their not being able to attend a course, which was mainly lack of training centres in the vicinity of their home or lack of awareness about training centres that offer the course.

Awareness and reach of government programmes to promote skill-building and employment generation were limited (Figure 6). One-fifth of boys and between one-quarter and one-third of girls, for example, had heard about the Uttar Pradesh Skill Development Mission. Even fewer older adolescents were aware of any vocational training centres that offer training under this mission-just eight percent of boys and 5-8 percent of girls. Employment exchange or counselling centres were known to a small proportion of adolescents-19 percent of boys and 11-14 percent of girls. The majority of adolescents-more boys than girls-were aware of the MNREGA scheme (67\% versus 54-56\%). Awareness of schemes that give loans to men and women for self-employment was reported by a relatively large proportion-44 percent of boys and 44-46 percent of girls. Findings also show that hardly any adolescents had benefited from employment-generation schemes.

Figure 6: Awareness of government programmes for skill-building and employment generation, Uttar Pradesh, 2015-16

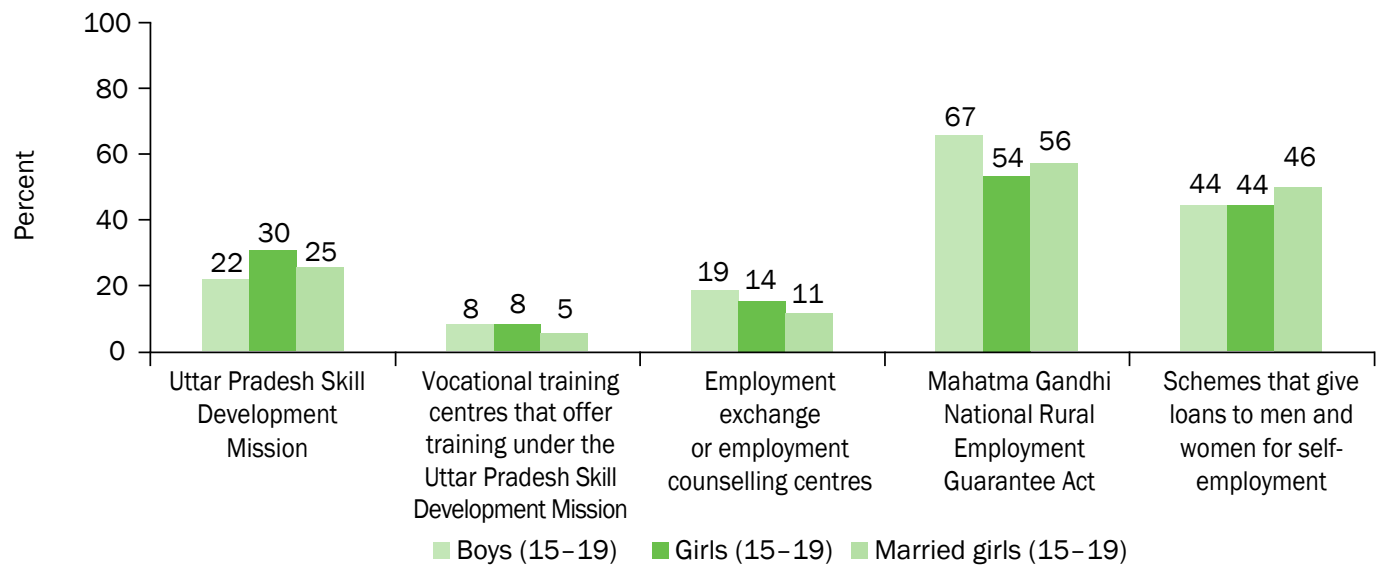

\section{Migration experiences}

Data on migration experiences among older adolescents show that 19 percent of boys, 14 percent of unmarried girls, and 92 percent of married girls were migrants by place of last residence. The major reason for migration among boys and unmarried girls was family migration-47 percent of boys and 68 percent of unmarried girls reported that they had moved into their current place of residence because the family had migrated. Other reasons for migration included the pursuit of education, economic distress experienced by family, and, additionally, among boys, employment. Almost all married girls who had migrated into their current place of residence cited marriage-related migration.

Finally, findings show that the vast majority preferred to stay in their state, given a choice -88 percent of boys and 70-76 percent of girls. Just 7-12 percent preferred to migrate outside their state, while the remaining were unsure about it. 
Findings suggest that large proportions of adolescents were exposed to the mass media, typically television and films (90-92\% of boys and $73-81 \%$ of girls). Fewer adolescents had been exposed to the print media (65-82\% of boys and $48-67 \%$ of girls who had completed five or more years of education) and to the radio (28-33\% of boys and $16-$ $24 \%$ of girls). More boys than girls reported exposure to each medium, while differences by age and by marital status among girls were modest for the most part. Differences between those from rural and those from urban areas were modest among boys with respect to exposure to most media. However, differences among girls between those from rural and those from urban areas were wider than among boys and were apparent across all media, except radio, with urban girls more likely than rural girls to report such exposure.

Fewer adolescents reported frequent exposure to the mass media as defined by daily or weekly exposure to various media (68-69\% of boys and $46-58 \%$ of girls to television; $67 \%$ of boys and $38-42 \%$ of girls to films; $10-14 \%$ of boys and $6-10 \%$ of girls to radio; and $38-61 \%$ of boys and $13-30 \%$ of girls who had completed Class 5 or above to print media). Frequent exposure to the mass media varied by caste, educational level, current schooling status, household economic status, mother's education, and rural or urban residence.

A large majority of adolescents owned or had access to a family member's mobile phone. Specifically, 1-8 percent of younger adolescents and between nine percent and 57 percent of older adolescents owned a mobile phone. Older adolescents, boys, and married older girls were more likely than their corresponding opposite categories to own a mobile phone. Some 72 percent and 37 percent of younger and older boys, respectively, and 60-75 percent of all three categories of girls reported that they did not own a phone but could use a family member's phone. On the whole, 81-94 percent of boys and 61-93 percent of girls owned or had access to a family member's mobile phone. Among these adolescents, notable proportions had watched films through the phone-39-53 percent of boys and 24-46 percent of girls. In contrast, a very small proportion of adolescents (2-5\%) reported having received health information through them.

\section{Figure 7: Percentage of adolescents who owned or who could access a family member's mobile phone, Uttar Pradesh, 2015-16}

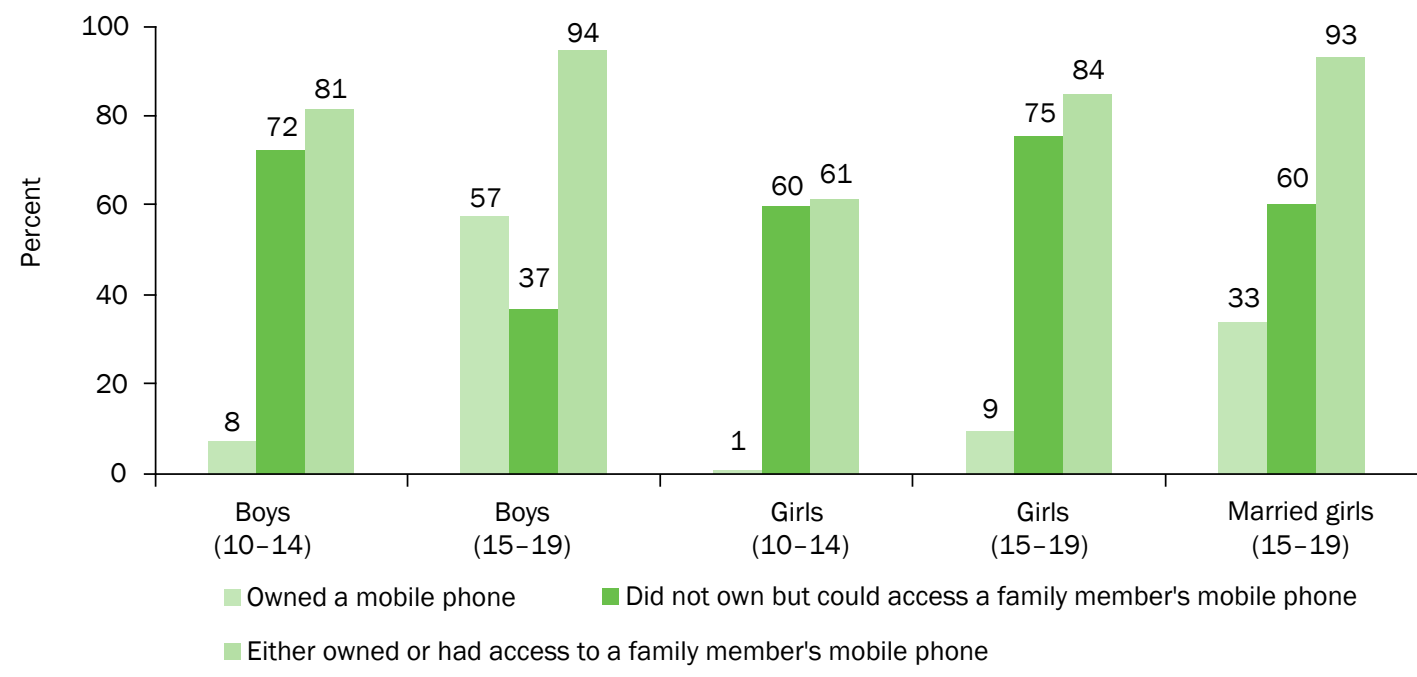

Findings show that the penetration of internet and social media among adolescents was very limited, except among older boys. While as many as 42 percent of older boys had ever accessed the internet, only 5-17 percent of adolescents in the remaining four categories had done so. More of older adolescents than younger adolescents, more of boys than girls, and more of unmarried older girls than married older girls accessed the internet. As expected, there were wide differences between urban and rural adolescents, with a larger proportion of urban than rural adolescents reporting access to the internet. Among adolescents who had ever accessed the internet, 29 percent of younger boys, 50 percent of younger girls, and 25 percent of unmarried older girls reported that they needed to take permission from their parents or other elders in the family to access the internet. In comparison, fewer older boys (8\%) and married older girls (17\%) required permission. Among adolescents who had ever accessed the internet, 14-16 
percent of boys and 21-35 percent of girls reported that they had accessed health information from the internet, with negligible differences between rural and urban adolescents. Very few adolescents, except older boys, had ever accessed social media-28 percent of older boys and 2-8 percent of adolescents in the remaining four categories. As expected, a larger proportion of urban than rural adolescents had ever accessed social media. Findings also confirm that internet and social media are currently reaching the 'privileged' adolescents, that is, boys, those belonging to general castes, educated adolescents, those currently attending school, those belonging to economically better-off households, those whose mother were educated, and those residing in urban areas.

Findings also suggest that more than two in five older boys (44\%), one in 20 unmarried older girls (5\%), and more than one in four married older girls (28\%) watched pornographic films. Of those who had ever accessed the internet, 46 percent of boys and 22-28 percent of girls had accessed pornographic materials on the internet, with modest differences between those from rural and those from urban areas. On the whole, 48 percent of older boys, seven percent of unmarried older girls, and 29 percent of married older girls were exposed to pornographic materials by way of films or the internet.

Findings also show that 1-3 percent of boys and girls had experienced harassment over mobile phones, and less than one percent of boys and girls had experienced harassment over the internet. Among older boys who had access to mobile phones, two percent had ever harassed someone using mobile phones. Likewise, among older boys who had accessed the internet, two percent had ever harassed someone over the internet.

Finally, findings show that five percent of younger boys and 26 percent of older boys who had access to a mobile phone, the internet, or social media had made new friends using these communication technologies as had 1-6 percent of girls. A larger proportion of adolescents perceived that they had acquired information related to various matters using these communication platforms-14-34 percent of boys and 9-21 percent of girls.

\section{Socialisation experiences and communication with parents}

Findings underscore, in general, the gender discriminatory experiences of adolescents. Among adolescents with opposite-sex siblings who were up to three years younger or older than the respondent, for example, 16-19 percent of boys reported that their parents favoured them over their sisters and 26-28 percent of girls (married older girls were not included), acknowledged that their parents favoured their brother over them in at least one of three practices, namely, the quantity or quality of food items given, the amount of pocket money given, the type of school in which they were enrolled, or parental aspirations for respondent's education. Girls who were less educated, out-ofschool, engaged in paid work, belonging to poor households, and residing in rural areas were more likely than others to report gender discriminatory experiences.

Adolescents' family lives were marked by violence, both witnessed and experienced. As many as 20-24 percent of boys and 26-30 percent of girls whose both parents were alive at the time of the interview had ever witnessed incidents where their father had beaten their mother. Some 6-12 percent of boys and 8-14 percent of girls (married older girls were not included) had witnessed incidents where their father had beaten their mother in the year preceding the interview. Large proportions of adolescents with at least one parent alive at the time of the interview reported that they had experienced physical violence perpetrated by a parent since the time they were 10 years of age (54-71\% of boys and $30-49 \%$ of all categories of girls). Experience of physical violence perpetrated by a parent in the year preceding the interview was reported by 52 percent of younger boys, 14 percent of older boys, 35 percent of younger girls, and nine percent of unmarried older girls. Slapping was the most common form of physical violence perpetrated by parents, which 52-68 percent of boys and 30-46 percent of girls reported. Other forms of violence included punching with fist or something that could hurt the respondent, kicking, dragging, or beating the respondent, pushing, shaking, or throwing something at respondent, and twisting the respondent's arm or pulling his or her hair.

Findings related to communication between adolescents other than married girls with their parents in the year preceding the interview on issues relevant to adolescents-such as school performance, friendship, being teased or bullied, and such physical changes during adolescence as voice change and facial hair growth (boys)/menstruation (girls), and reproductive processes-reiterate findings from other studies showing that such communication was far from universal. Just 31-35 percent of boys and 22-23 percent of younger and unmarried older girls reported, for example, that they had discussed their friends with their father in the year preceding the interview. More 
adolescents-40-46 percent of boys and 61-68 percent of younger and unmarried older girls-had discussed their friends with their mother during the same reference period. Moreover, fewer adolescents had discussed sensitive topics-such as being teased or bullied, physical changes during adolescence, and reproductive processes-with either parent; for example, just 1-2 percent of older boys and younger girls and unmarried older girls reported that they had discussed reproductive processes with their father or mother in the year prior to the interview.

Over two-fifths of boys (41-45\%) and between one-quarter and two-fifths of girls had a role model (Figure 8). Of those who reported a role model, the majority reported someone from their family-65-67 percent of boys and 58-77 percent of girls. Both boys and girls were more likely to report a same-sex over an opposite-sex family member as their role model. Teachers were the leading non-family role models reported by adolescents among all categories of adolescents, except by older boys, who reported friends and neighbours as leading role models. Only a small proportion of adolescents-11-13 percent of boys and 2-6 percent of girls-reported such high-profile personalities as actors, politicians, or sportspersons as their role models.

\section{Figure 8: Percentage of adolescents who reported having a role model, Uttar Pradesh, 2015-16}

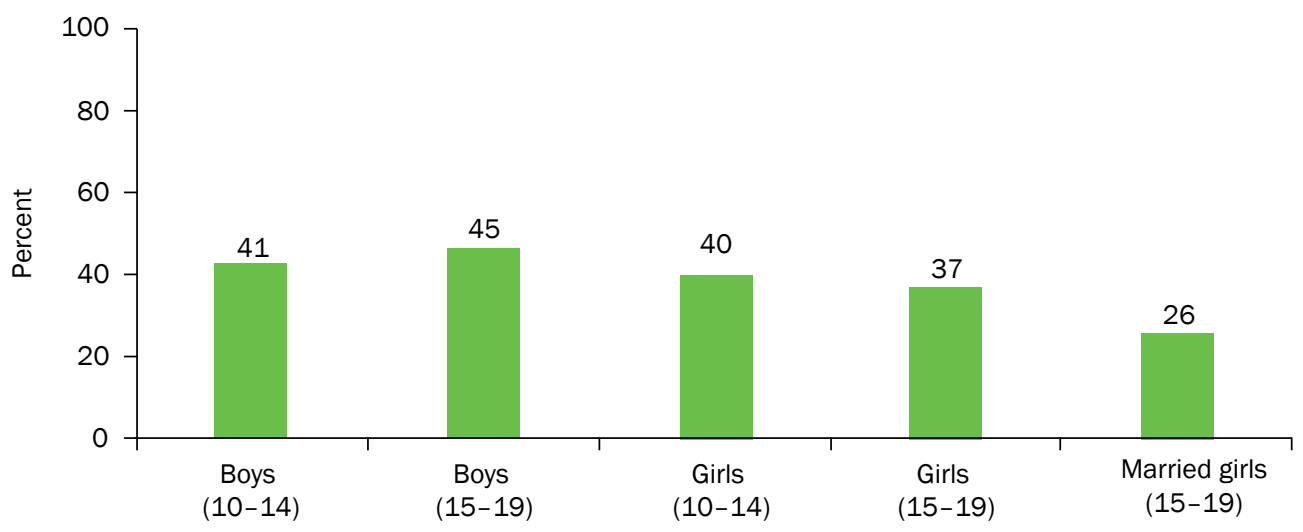

The leading confidante for younger adolescents to discuss such personal matters as experience of teasing or bullying and a problem in the private parts tended to be their mother. As far as older adolescents are concerned, no consistent picture was apparent. While older boys identified several leading confidantes to discuss a problem in the private parts-a parent (24-27\%), a friend (18\%), and a healthcare provider (19\%)-mothers were overwhelmingly identified as the leading confidante for unmarried older girls (79\%), and husbands and mothers were similarly identified by married older girls ( $56 \%$ and $33 \%$, respectively). However, most categories of adolescents rarely mentioned their mother or father as the leading confidante to discuss matters related to opposite-sex friends and/or romantic partners. In comparison, adolescents derived an important measure of support from their peer networks on such personal matters as relationship with an opposite-sex friend or romantic partner. Friends were by far the leading confidante on such matters for both younger and older boys and unmarried older girls.

Leading individuals from whom all adolescents, irrespective of age, sex, place of residence, and, among older girls, of marital status, learned social behaviours were their mother (reported by $77-82 \%$ of boys and $80-84 \%$ of girls), followed by their father (reported by $75-79 \%$ of boys and $58-62 \%$ of girls). Teachers also constituted a major source for learning social behaviours for all categories of adolescents, except for married older girls $(36-51 \%$ of boys and $25-32 \%$ of girls).

\section{Peer networks and interaction}

Adolescence was associated with close peer networks for most participants. Almost all adolescents reported that they had some friends, except for about one in ten married older girls who reported that they had no friend. Older boys reported a larger peer network than did the other categories of adolescents (average of four and three friends, respectively). Findings also show that the majority of adolescents, except married older girls, spent time with their friends often (86-93\% of boys and $68-88 \%$ of girls); most married older girls reported that they met their friends sometimes (90\%), presumably because their friends resided in their natal homes. At the same time, 
findings underscore the lack of social spaces in which adolescents can network with their peers. Most adolescents, irrespective of age, sex, and, among older girls, of marital status, reported that they typically met their friends either in school/college or at each other's homes. Just 1-4 percent of girls compared with 28-31 percent of boys typically met their friends in social spaces such as a playground, a garden, or adolescents' groups or clubs. Moreover, only small proportions of adolescents were members of any group, with little variation by age, sex, or, among older girls, by marital status ( $7-10 \%$ of boys and $3-5 \%$ of girls).

\section{Aspirations, agency, and gender role attitudes}

Findings related to adolescents' plans for the immediate future, that is, for the three years following the interview, show that the vast majority of younger boys and girls (84-87\%) reported that they would like to continue/get back to their studies. In contrast and not surprisingly, the vast majority of older boys and unmarried older girls reported plans related to livelihood generation ( $69 \%$ of boys and $51 \%$ of girls) and to continue/get back to their studies (56\% of boys and $53 \%$ of girls). Fewer married older girls reported such plans (45\% and 9\%, respectively). Girls, in addition, reported plans to get married, or become a mother, or assume the role of a homemaker. Longer-term aspirations, that is, aspirations for their adulthood years varied by sex of the respondent. Several boys aspired to join the police or armed forces (21-24\%), become a doctor ( $20 \%$ and $8 \%$ of younger and older boys), or start a business ( $8 \%$ and $21 \%$ of younger and older boys), while girls preferred to become a teacher ( $26-31 \%$ of younger and unmarried older girls and $11 \%$ of married older girls). Married older girls additionally preferred to become a homemaker (25\%). Findings also show that large proportions of adolescents did not think about what profession or vocation they would like to follow in future, with more girls than boys reporting so (32-44\% and $23-26 \%$, respectively).

Findings clearly highlight the limited agency of adolescents and the striking gender divide in all the dimensions of adolescents' agency. Adolescent girls were far more disadvantaged than adolescent boys. Differences by gender, for example, were evident among both younger and older adolescents across all domains of decision-making, with boys more likely than girls to have some say in decisions such as choice of friends, level of schooling they want, whether to work or not, etc. Thus, 61 percent of younger boys compared with 41 percent of younger girls reported participation in decision-making in the three issues that we probed among younger adolescents in the study. Similarly, 49 percent of older boys compared with 22-25 percent of unmarried and married older girls reported participation in decisionmaking in the three issues probed among them. Where comparisons across age groups were possible as in decisions related to the level of schooling that respondents should have, findings show that more older girls than younger boys said others only would make the decision. Likewise, boys reported greater mobility than girls, regardless of the locations, age, and residence; 69 percent and 97 percent of younger and older boys, respectively, had freedom to visit at least two locations unescorted compared with 35 percent of younger girls, 38 percent of unmarried older girls, and 13 percent of married girls. Such differences were evident even in terms of freedom for younger adolescents to play in the open spaces of the village or ward; 92 percent of boys compared with 54 percent of girls were allowed to do so.

Access to and control over financial resources tended to be limited among both boys and girls: 44 percent of younger boys and 58 percent of older boys reported some savings as did 45 percent of younger girls and 63-68 percent of older girls. Even fewer-16 percent of younger boys, 45 percent of older boys, 26 percent of younger girls, and 33-46 percent of older girls owned a bank/post office account either independently or jointly with someone else (Figure 9). Differences by sex were stark with regard to operation of savings accounts among older adolescents: 83 percent of boys who owned an account reported operating it themselves compared with 64-69 percent of girls. However, large proportions of adolescents, regardless of age, sex, and, among older girls, marital status, reported some level of self-efficacy in expressing their views in public and private spaces as well as in resisting or confronting those who misbehave with them.

While adolescent boys were not as disadvantaged as adolescent girls, findings indicate that many boys were also not able to exercise agency in their everyday lives. Thus, only 49 percent of older boys reported some say in all three age-appropriate decisions that we probed in the study. Less than half of older boys owned a bank/post office account either independently or jointly with someone else. 
Figure 9: Percentage of adolescents who owned a bank/post office account, Uttar Pradesh, 2015-16

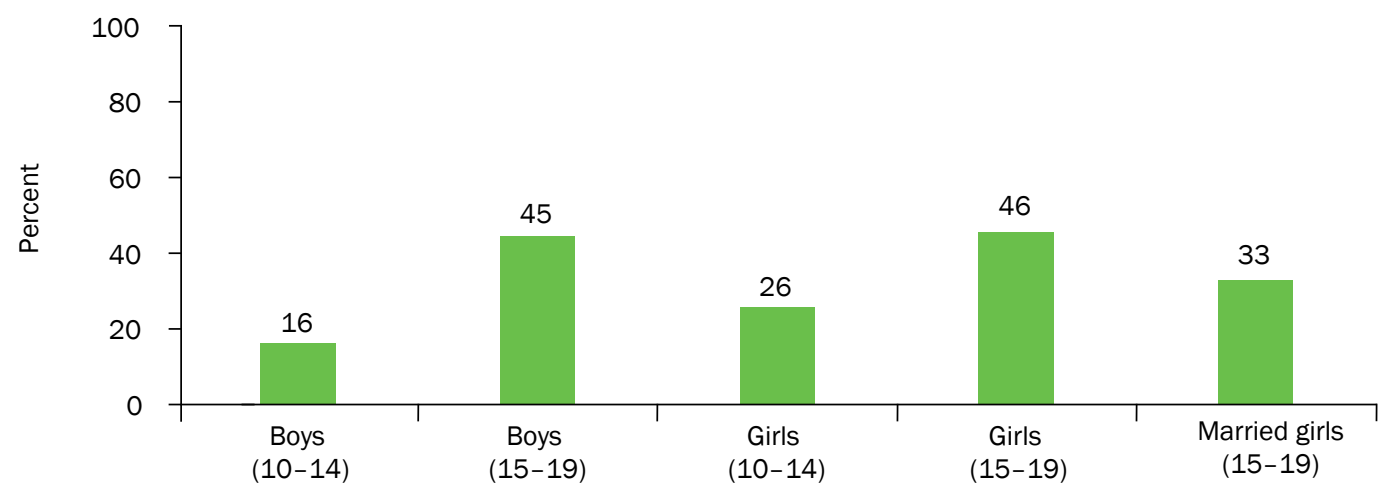

Findings also highlight the disadvantages experienced by married girls. Mobility, for example, was much more restricted among married older girls than their unmarried counterparts; just 24 percent of married older girls compared with 71 percent of unmarried older girls were allowed to visit a shop, market, or friend's or relative's house within their village or ward on their own. They were also less likely than unmarried older girls to own a savings account (33\% versus $46 \%$ ), even though they were somewhat more likely to have some savings (68\% versus $63 \%$ ).

Finally, 48 percent of younger boys and 71 percent older boys reported gender egalitarian attitudes on most issues as did 70 percent of younger girls and 66-72 percent of unmarried and married older girls. Adherence to egalitarian attitudes was positively associated with age, years of schooling, household economic status, mother's education, and residence in rural or urban areas.

\section{Awareness of sexual and reproductive matters}

Findings underscore adolescents' limited awareness of sexual and reproductive matters, such as how pregnancy occurs and knowledge of contraception, HIV and safe sex practices, and maternal and newborn care practices. Just 55 percent of younger boys in ages 13-14 and 43 percent of younger girls in ages 13-14, for example, knew that a woman cannot become pregnant after kissing or hugging; even fewer (8-10\%) were aware that a woman can get pregnant at first sex. Among older adolescents, as seen in Figure 11, only 23-24 percent of boys and unmarried girls were aware that a woman can get pregnant at first sex, and hardly any (5-7\%) knew that a woman is most likely to become pregnant if she engages in sexual relations mid-cycle (Figure 10). Even among married older girls, just 58 percent were aware of even one of these facts. However, as many as 26 percent of younger boys (ages 10-14) and 57 percent of older boys were aware of the availability of tests to determine the sex of the foetus as were 30 percent of younger girls (ages 10-14) and 65-68 percent of unmarried and married older girls.

Figure 10: Percentage of adolescents in ages 15-19 reporting awareness of selected sex- and pregnancy-related matters, Uttar Pradesh, 2015-16

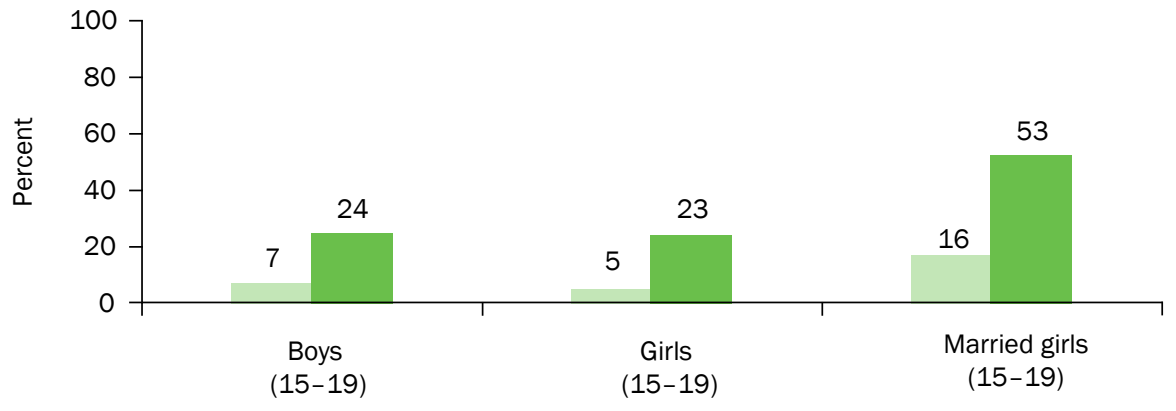

$\square$ A woman is most likely to get pregnant if she has sex half-way between her periods

- A woman can get pregnant at first sex 
While most older adolescents had heard of contraception, in-depth awareness was limited (these questions were not posed to younger adolescents). Thus, 88 percent of boys, 63 percent of unmarried girls, and 93 percent of married girls had heard of at least one selected modern method of contraception-oral pills, condoms, and emergency contraceptive pills-suitable for adolescents. However, specific knowledge of at least one modern contraceptive method was reported by considerably fewer-73 percent of boys, 17 percent of unmarried girls, and 63 percent of married girls. Awareness levels increased with the respondent's educational attainment level as well as his/her mother's educational attainment level and the household's economic status.

On issues related to HIV/AIDS and STIs, we asked younger adolescents only about awareness of HIV/AIDS, while older adolescents were asked about HIV/AIDS as well as STIs. Awareness of HIV/AIDS was limited-just 9-11 percent of younger boys and girls, 57 percent of older boys, and 30-37 percent of unmarried and married older girls had heard about HIV/AIDS. Comprehensive awareness of HIV/AIDS was even more limited-just two percent of younger adolescents and 6-7 percent of unmarried and married older girls, and 17 percent of older boys reported comprehensive awareness of HIV/AIDS. Awareness of STIs other than HIV/AIDS was also limited among older adolescents-just 19-20 percent of older boys and unmarried older girls and 37 percent of married older girls had heard about STIs.

Findings highlight the limited awareness of maternal and newborn care practices among older adolescents, including among married girls (younger adolescents were not asked about these matters). Just 25-32 percent of boys and girls, for example, knew that a pregnant woman should have at least four antenatal check-ups, and 58-62 percent of boys and girls knew that a woman should go for post-partum check-ups even if she feels well. Similarly, 28-42 percent of boys and girls knew that a newborn should be breastfed within an hour of birth, 39-50 percent knew that colostrum should be fed to the newborn, and 24-39 percent knew that an infant should be breastfed exclusively for six months. Finally, 63 percent of boys and 40-44 percent of girls reported that a newborn should not be bathed on the first day of birth. Awareness levels increased with the respondent's educational attainment level, current enrolment status, his/her mother's educational attainment level, and the household's economic status.

Findings pertaining to adolescents' perceptions about abortions underscore that most adolescents did not favour the termination of pregnancy; one-third or fewer adolescents (23-32\%) perceived that it is acceptable for a girl or woman to terminate her pregnancy if she does not want to continue with it. Indeed, as many as 54-64 percent of adolescents believed that it is not acceptable to terminate a pregnancy. Of those who were aware of abortion, 66 percent of boys and 51-61 percent of girls reported that they would direct a friend or relative in need of abortion services to a provider or facility that was likely to be legal, which indicates some indirect understanding that abortion is legally available. Only very small proportions of adolescents reported that they would suggest a facility or provider not authorised to provide abortion services (2-5\%). Finally, 20 percent of boys and 12-29 percent of girls reported that they did not know of facilities that offer abortion services.

Awareness of the law related to the minimum age of marriage was far from universal among younger adolescents-49 percent of younger boys and 41 percent of younger girls reported that there is a legal minimum age of marriage for males and females in India (Figure 11). Awareness of the law was reported, in contrast, by larger proportions of older adolescents-86 percent of boys and 77 percent of unmarried and married girls. Awareness of the correct legal minimum age of marriage for females and especially for males was more limited. Thus, 24 percent of younger boys and 62 percent of older boys correctly reported that 18 years is the legal minimum age of marriage for females as did 21 percent of younger girls and 54-56 percent of unmarried and married older girls. Similarly, 9-10 percent of younger boys and girls, 29 percent of older boys, and 29-33 percent of unmarried and married older girls reported that 21 is the legal minimum age of marriage for males. 
Figure 11: Percentage of adolescents in ages 10-19 who had correct knowledge of the legal minimum age of marriage in India, Uttar Pradesh, 2015-16

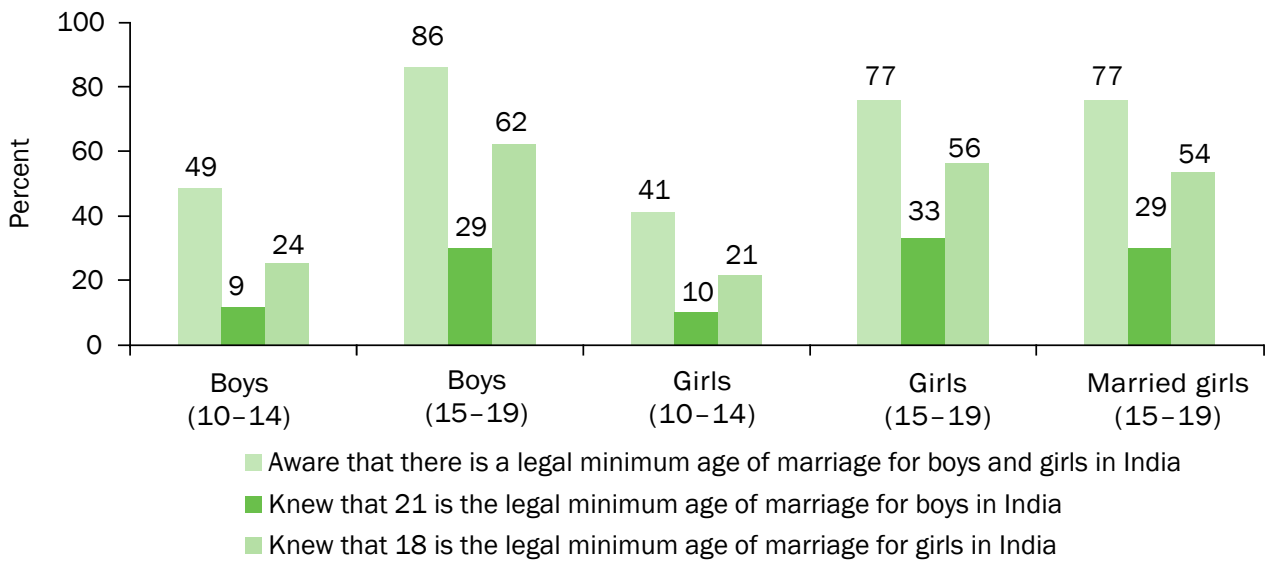

\section{Sources of information on sexual and reproductive matters}

Adolescents had few sources of information on puberty and sexual and reproductive matters. Indeed, large proportions of younger boys and girls had never received any information about puberty ( $56 \%$ and $63 \%$, respectively). Likewise, 69 percent of younger boys in ages 13-14 and 83 percent of younger girls in ages 13-14 had never received information on such matters as how pregnancy occurs or how a pregnancy can be prevented as also 37 percent, 57 percent, and 31 percent of older boys, unmarried older girls, and married older girls, respectively (adolescents in ages 10-12 were not asked about these matters).

Leading sources of information on puberty for younger adolescents were family members, particularly parents $(12 \%$ of boys and $28 \%$ of girls), followed by friends (11\% of boys and $4 \%$ of girls) and influential adults in the community, particularly teachers ( $9 \%$ of boys and $6 \%$ of girls). Hardly any younger adolescents listed healthcare providers (less than $1 \%$ ) or the mass media (less than $2 \%$ ) as their major sources of information. Leading sources of information on sexual and reproductive matters for boys aged 13 and above included friends (17\% among younger boys in ages $13-$ 14 and $48 \%$ among older boys), influential adults in the community (6\% and $14 \%$ among $13-14$-year-old boys and older boys, respectively), and the mass media ( $2 \%$ and $14 \%$ among $13-14$-year-old boys and older boys, respectively). Among girls, while no single leading source of information was identified among younger girls, family members $(24 \%)$, friends (13\%), and the mass media (13\%) were listed as leading sources for unmarried older girls, and family members (60\%), friends (16\%), and influential adults in the community (7\%) were listed among married older girls.

Large proportions of younger adolescents preferred to receive information on puberty from a family member, particularly parents (34\% of boys and $62 \%$ of girls), followed by influential adults in the community, particularly teachers ( $29 \%$ of boys and $11 \%$ of girls), and friends ( $19 \%$ of boys and $9 \%$ of girls). Friends and influential adults in the community (mainly teachers and healthcare providers) were also preferred channels through whom to receive information on sexual and reproductive matters for younger boys (ages 13-14) and older boys (25\% and 44\%, respectively, with regard to friends and $29 \%$ and $38 \%$, respectively, with regard to influential adults in the community). Family members and friends constituted the most preferred channels to receive sexual and reproductive health information for both younger girls (ages 13-14) and unmarried and married older girls; 47 percent of younger girls, 54 percent of unmarried older girls, and 73 percent of married older girls preferred family members, and nine percent, 16 percent, and 12 percent, respectively, preferred friends. Unmarried and married older girls, additionally, preferred influential adults in the community, mainly healthcare providers $(17-19 \%)$. Hardly any girls indicated a preference to receive such information from the mass media (3-7\%).

\section{Exposure to family life or sex education programmes}

Few adolescents aged 13 and above-5-9 percent of boys and 9-18 percent of girls-had ever attended family life or sex education programmes either in or outside the school setting. The majority of boys who had received such 
education reported that it covered modes of HIV transmission and its prevention (88\%), followed by the subject of pregnancy and relationships between boys and girls (32-33\%), with far fewer reporting that they had been informed about nocturnal emission (19\%). The topic that was recalled by the largest proportion of girls was that on menstruation, recalled by $73-85$ percent, followed by modes of HIV transmission and its prevention (61\%). Findings suggest, moreover, that adolescents who had undergone family life or sex education were more likely than those who had not to report in-depth awareness of sex and pregnancy matters, contraception, comprehensive awareness of HIV/ AIDS, and maternal and newborn care practices (Figure 12).

Figure 12: Percentage of adolescents in ages 15-19 who had received formal family life or sex education by topics covered in the programme,* Uttar Pradesh, 2015-16

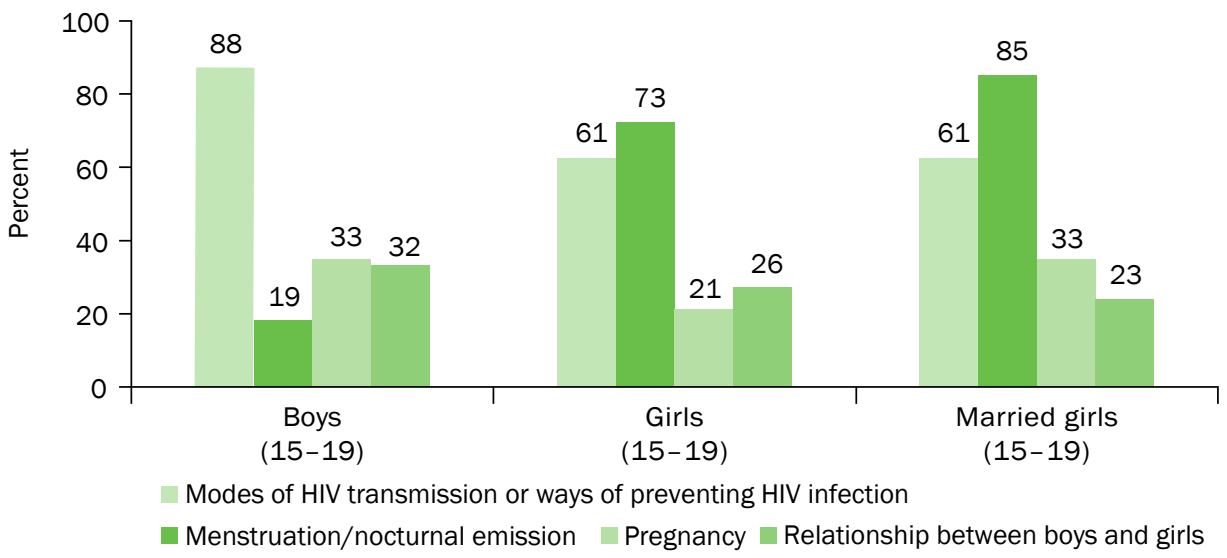

Note: * Of those who had ever received formal family life or sex education.

\section{Premarital romantic and sexual experiences}

Only older adolescents were asked questions on romantic and sexual relationships. Findings confirm that despite strict norms prohibiting opposite-sex socialising, opportunities do exist for the formation of romantic relationships among adolescents. As many as 26 percent of older boys and 16-20 percent of unmarried and married older girls reported that they had been involved in a romantic partnership in their lifetime. Figure 13 shows that romantic relationships almost always included some form of physical intimacy-74 percent of boys and 54-60 percent of girls had hugged their romantic partner, and progressively fewer reported more intimate behaviours, such as kissing their romantic partner on the lips (68\% of boys and $42-51 \%$ of girls) and engaging in sexual relations with their partner (42\% of boys and $18-25 \%$ of girls).

Figure 13: Percentage of adolescents in ages 15-19 reporting a premarital romantic relationship by experiences of physical intimacy and sex with their romantic partner, Uttar Pradesh, 2015-16

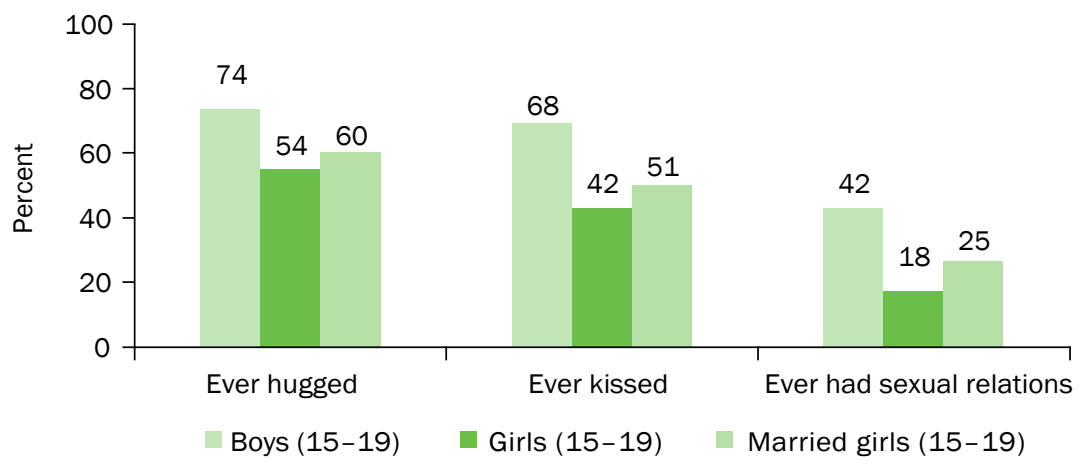

A large proportion of older adolescents who had reported sexual relations with a romantic partner had engaged in unprotected sex. Contraceptive use in a romantic relationship was limited-only a quarter of boys and about onefifth of girls reported that they had used a contraceptive method at first sex. Even more limited was consistent 
contraceptive use-only 16 percent of boys and 10-12 percent of girls reported that they/their partner had always practised contraception. The majority of those who practised contraception in romantic relationships had used condoms.

On the whole, 17 percent of older boys and six percent of unmarried older girls reported a sexual experience, and 10 percent of married older girls reported a sexual experience before marriage (Figure 14).

Figure 14: Percentage of adolescents in ages 15-19 reporting premarital sexual experiences with opposite-sex partners, * Uttar Pradesh, 2015-16

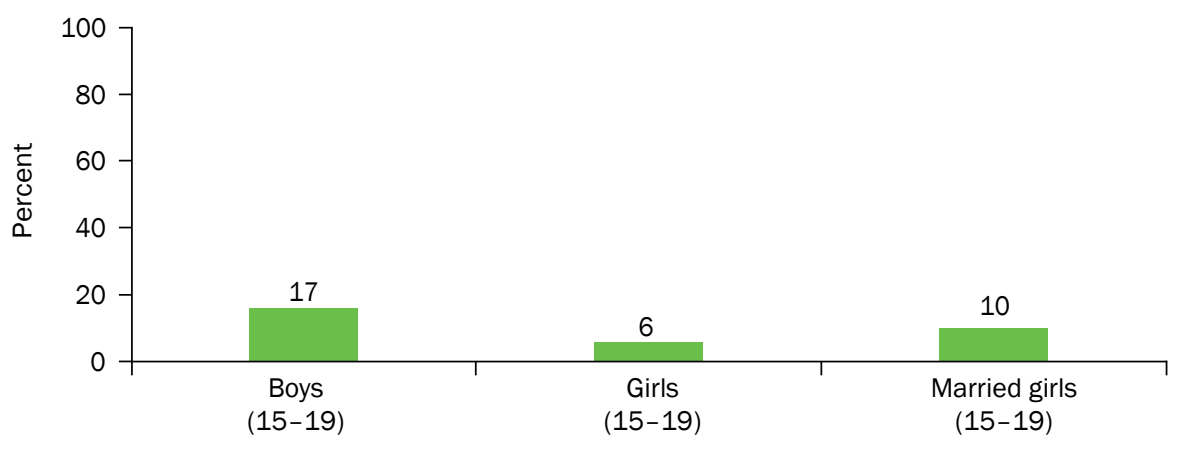

Note: *Percentage who reported premarital sexual experiences in the course of face-to-face interview or anonymously in a sealed envelope method.

As expected, sexual experiences took place largely with a romantic partner. Smaller numbers of boys reported that they had forced a girl to have sex and had engaged in sex with a married woman or a casual partner, and girls similarly reported that they had been forced to engage in sex. Many of them reported early and risky sexual experiences-for example, 24 percent of boys and 14-15 percent of girls who had sexual experiences reported that they had engaged in sex before age 15, and 34 percent of boys and 12 percent and 23 percent of unmarried girls and married girls, respectively, reported multiple partners. Moreover, consistent condom use was limited-only 14 percent of boys and 5-8 percent of girls reported condom use in all sexual encounters.

Among boys and unmarried girls who had ever engaged in sex with an opposite-sex partner, 76 percent and 80 percent, respectively, had engaged in sexual relationships in the 12 months preceding the interview. Of those who had engaged in sexual relationships in the 12 months preceding the interview, 28 percent of boys and one percent unmarried girls reported sex with multiple partners, and 16 percent of boys and 5 percent of unmarried girls reported condom use in all sexual encounters during the 12 months prior to the survey.

Six percent of boys and one percent and five percent of unmarried girls and married girls, respectively, who had reported a premarital sexual relationship in the face-to-face interview reported a premarital pregnancy.

Finally, one percent of older adolescents reported that they had been romantically or sexually attracted to a same-sex person, and one percent or fewer had engaged in an intimate relationship with a same-sex partner.

\section{Non-consensual sexual experiences}

Non-consensual sexual experiences characterised the lives of a significant number of adolescents. As many as 16 percent of younger girls had ever experienced teasing and verbal harassment of a sexual nature and two percent had experienced unwanted sexual touch. Among younger boys, three percent had ever experienced non-consensual sexual touch, typically perpetrated by another boy or a man.

Two percent of older boys and 8-9 percent of unmarried and married older girls reported ever experience of nonconsensual sexual touch, including attempts to force sex on them (married older girls were asked to report such experience if it had occurred before their marriage). Four percent of unmarried older girls and five percent of married older girls reported the experience of a forced sexual encounter ever in life including that perpetrated by their romantic partner/s (married older girls' experiences were before marriage). 
Some three percent of younger boys and as many as 20 percent of older boys had ever verbally harassed a girl in a sexual way. Far fewer-less than one percent of younger boys and two percent of older boys-admitted to their having ever perpetrated sexual touch on girls when they did not want to be touched, or attempting to force sex on a girl, and five percent of older boys reported the perpetration of forced sex, including on their romantic partner/s.

\section{Transition to marriage and early married life}

Findings related to adolescents' age preferences for marriage show that large proportions of adolescents -68 percent of younger boys, 81 percent of younger girls, 40 percent of older boys, and 53 percent of unmarried older girls-had not thought about the age at which they would like to marry. Among older adolescents, hardly any girls (or boys) preferred to marry below age 18 , the legal minimum age of marriage for females, although a significant minority of boys $(7 \%)$ and notable proportions of girls (18\%) preferred to marry before age 21 , that is, the legal minimum age of marriage for males. Findings also show that the large majority of adolescents reported that they did not know the preferred age at which their parents would like them to marry, which is perhaps a reflection of the limited communication between adolescents and parents on these matters, the exclusion of adolescents in marriage-related decisions, and the fact that many parents may not have started thinking about it, particularly for younger adolescents. For older adolescents for whom data on both respondents' preferences and perceived parental preferences as reported by adolescents were available, a comparison shows that the majority of boys reported that the age at which they would like to marry and the age at which they perceived that their parents preferred them to marry was identical, while the majority of girls reported that they preferred to marry at ages later than what they thought their parents preferred.

Findings confirm the prevalence of child marriage among girls, although marriages in early adolescence, that is, before age 15 were rare. Among girls in ages 15-19, just two percent were married before age 15 . However, among girls in ages 18-19, as many as 21 percent were married before age 18, with 24 percent in rural areas and 14 percent in urban areas. Although not exactly comparable, our findings concur with evidence from the National Family Health Survey 2015-16, which reported that 21 percent of 20-24-year-old women were married before age 18 (IIPS, 2017). The median age at both marriage and cohabitation among the married girls was 17 years.

Adolescent girls' involvement in marriage-related decisions was limited. As many as 34 percent of married girls reported that their parents had never consulted them on the age they wish to marry. An overwhelming proportion $(92 \%)$ of girls had married a partner chosen by their parents. As many as 40 percent of girls reported that their parents had not sought their approval at all while choosing their marriage partner. Just eight percent of girls reported their having chosen their marriage partner on their own. Hence, not surprisingly, reported premarital acquaintance was limited. Just 37 percent of girls reported that they had ever had a chance to meet and interact alone with their husband-to-be prior to marriage. In contrast, 57 percent of girls reported that they had met their husband for the first time on the wedding day. These findings underscore the extent to which girls were excluded from marriage-related decision-making and the extent to which girls were married to relative strangers.

Despite the existence of laws against the practice of dowry, this practice characterised the marriages of 90 percent of girls. Rural girls were somewhat more likely than urban girls to report dowry. Findings also show that a notable proportion of girls acknowledged that they had experienced dowry-related harassment (15\%).

Violence within marriage was reported by considerable proportions of girls who had begun cohabiting with their husband, and of all forms of violence, sexual violence was the most commonly reported, while emotional violence was the least commonly reported (Figure 15). Thus, 19 percent of girls had experienced emotional violence ever in married life, that is, their husband had either verbally humiliated them in the presence of others or threatened to hurt or harm someone close to them. Some 24 percent reported the experience of some form of physical violence ever in married life. Somewhat more girls acknowledged the experience of forced sex within marriage (30\%). Slapping was the most commonly reported of all forms of physical violence experienced, and it was experienced by almost all those who had experienced any form of physical violence. Recent violence was reported by somewhat fewer-25 percent and 22 percent of girls who had cohabited for at least one year reported the experience of physical and sexual violence, respectively, in the year preceding the interview. 
Figure 15: Percentage of married girls in ages 15-19 reporting ever experience of emotional, physical, and sexual violence perpetrated by their husband, Uttar Pradesh, 2015-16

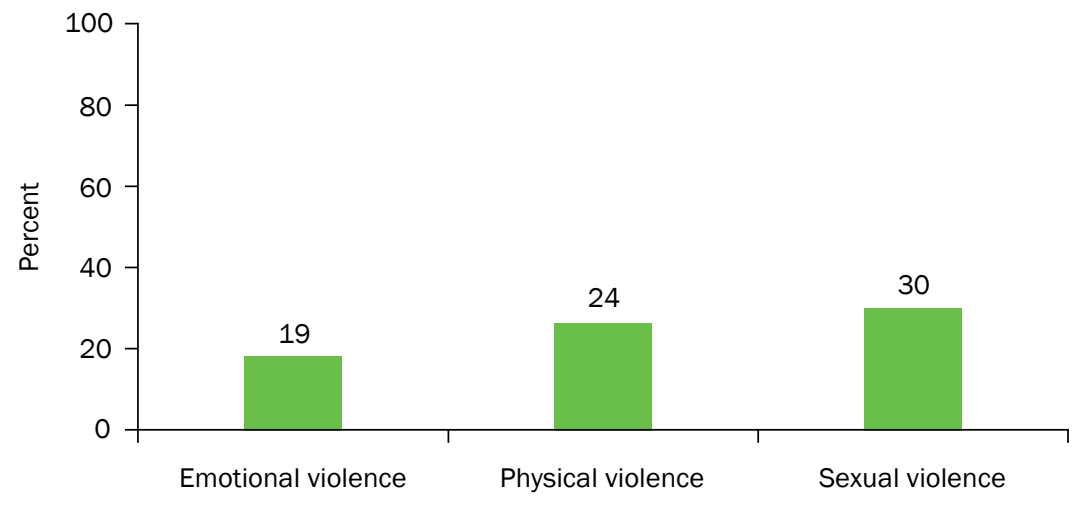

\section{Contraceptive practices}

Findings show that just 15 percent of girls who had begun cohabitation were advised to delay the first pregnancy about the time of their marriage. Moreover, communication with the husband on reproductive matters was far from universal. Just 59 percent of girls who had begun cohabitation reported that they had communicated with their husband about how many children they wanted to have. Far fewer reported that they had discussed contraception to delay the first pregnancy with their husband (24\%). At the same time, as many as 23 percent of girls who had begun cohabitation felt pressurised to bear a child soon after marriage. However, girls' preferences differed-indeed, some 43 percent of girls desired to delay their first birth for two years after marriage.

Contraceptive use at any time within marriage was limited-just 18 percent of girls reported ever use of contraceptives, 12 percent of girls reported its practice at the time of the interview, and 13 percent reported its practice to delay the first birth. Contraceptive methods most likely to be used were condoms, followed by rhythm and withdrawal. The leading reason for not using contraception to delay the first pregnancy by girls who had not done so despite a desire to delay their first birth by at least for two years was objections to family planning, particularly from their husband and other family members. They also cited lack of awareness about methods or sources for methods, issues related to access, method-related concerns, and infrequent sex. Some 33 percent of girls reported that they would use a contraceptive method in the next 12 months, and another 35 percent reported that they would use one sometime in the future.

A substantial proportion of married older girls had an unmet need for contraception-38 percent of married girls had an unmet need for spacing and six percent had an unmet need for limiting childbearing. On the whole, 43 percent of married girls had an unmet need for contraception, while 55 percent of married girls had a demand for contraception-48 percent for spacing and eight percent for limiting childbearing-and just 21 percent of the total demand for contraception was satisfied.

\section{Transition to motherhood}

Some seven percent of all girls, regardless of marital status, had begun childbearing-five percent had experienced a live birth and one percent of girls were pregnant with their first child. Data on age at first birth highlight that although childbearing in early adolescence, that is, before age 15, was rare, one in 10 girls in ages 18-19 had their first birth in childhood, that is, before age 18 .

Among those who had begun cohabiting, 56 percent of girls had ever been pregnant and one-third of girls reported at least one live birth. Findings also show that the first birth took place soon after cohabitation for many-for example, among girls who had cohabited for at least two years, 66 percent had their first child within two years of cohabitation.

Infant, neonatal, and post-neonatal mortality rates were measured. Findings show that the neonatal mortality rate stood at 62 deaths per 1,000 live births and post-neonatal mortality rate was 17 deaths per 1,000 live births. In total, infant mortality rate stood at 79 deaths per 1,000 live births. 
Pregnancy loss was considerable. As many as 12 percent of married girls experienced pregnancy loss. Two percent of married girls, for example, reported that their pregnancy had ended in a stillbirth, 10 percent reported miscarriage, and, one percent reported an induced abortion.

In addition, large proportions of married girls reported an unintended pregnancy. Among married girls who were not pregnant at the time of the interview, 40 percent reported that their last pregnancy was mistimed or unwanted. Among married girls who were pregnant at the time of the interview, 39 percent reported that their current pregnancy was either unwanted or wanted at a later time.

\section{Maternal and newborn health care practices for the first birth}

Circumstances of the first birth suggest that almost all married girls had received at least one antenatal checkup (95\%; Figure 16). However, fewer girls had their first check-up in the first trimester (47\%), while even fewer had received four or more antenatal check-ups (31\%). Although 55 percent of married girls had taken iron and folic acid tablets sometimes, only eight percent had taken it for 100 days. As many as 82 percent of married girls had received two or more tetanus toxoid injections and almost all (93\%) had received at least one. Giving birth in a health facility and having skilled attendance were far from universal for the first-and most risky-delivery. Indeed, just 72 percent of married girls reported that they gave birth in a health facility and 78 percent of married girls reported that their first birth was attended by a health care personnel. Findings show that girls' access to post-partum check-ups following their first birth was limited-just 37 percent of married girls reported at least one check-up. Some 33 percent of married girls had their first post-partum check-up within two days of delivery. Almost all married girls who had received a post-partum check-up had received it from a healthcare professional. Only eight percent of married girls had received three or more check-ups within six weeks of delivery.

Figure 16: Percentage of married girls in ages 15-19 who had received antenatal, delivery and post-partum care or their first birth, * Uttar Pradesh, 2015-16

Antenatal care

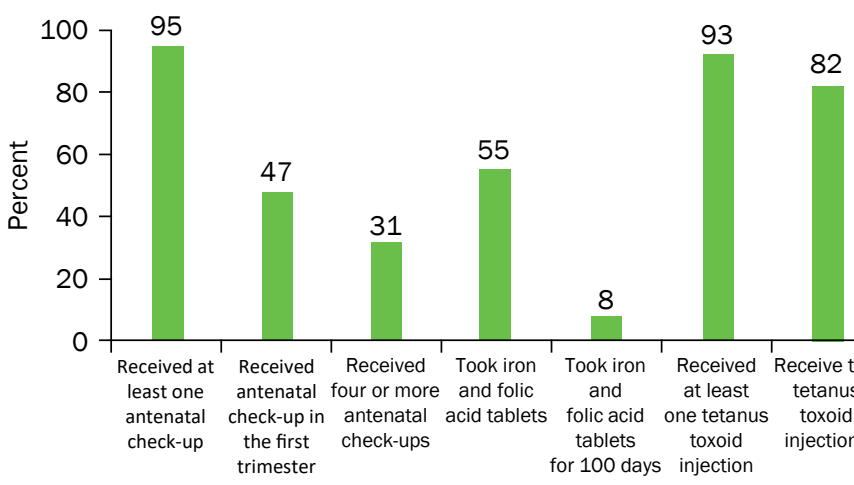

Delivery care

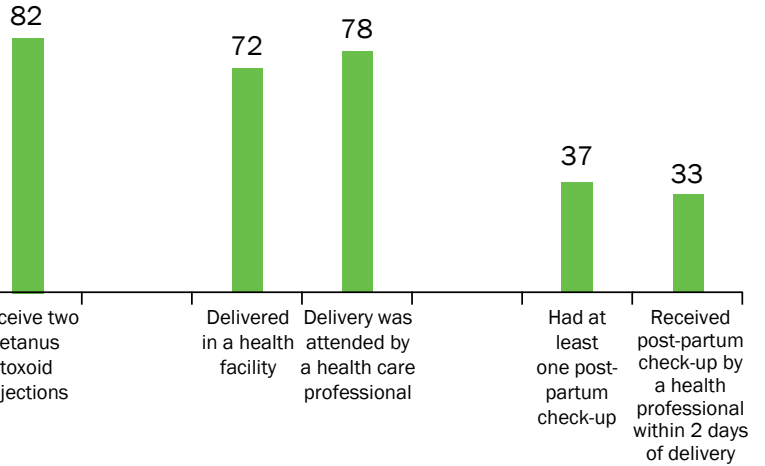

Note: * Of married older girls who had at least one live birth.

Breastfeeding is nearly universal-96 percent of married girls with at least one live birth reported that they had breastfed their first child (Figure 17). However, only a small proportion of married girls had initiated breastfeeding their first child within an hour of delivery (33\%). As many as 70 percent of married girls reported that they had initiated breastfeeding their first child within the first day of birth. The large majority of married girls who had breastfed their first child had done so day and night on demand in the first six months of birth (83\%). On the whole, 68 percent of first-born children under six months of age were exclusively breastfed. Immunisation of infants within the first month of life was not universal-87 percent, 89 percent, and 72 percent of mothers reported that their firstborn child had been administered a BCG vaccination, oral polio drops, and a Hepatitis-B vaccine, respectively, within one month of birth. 
Figure 17: Percentage of married girls in ages 15-19 reporting breastfeeding practices for their first child,* Uttar Pradesh, 2015-16

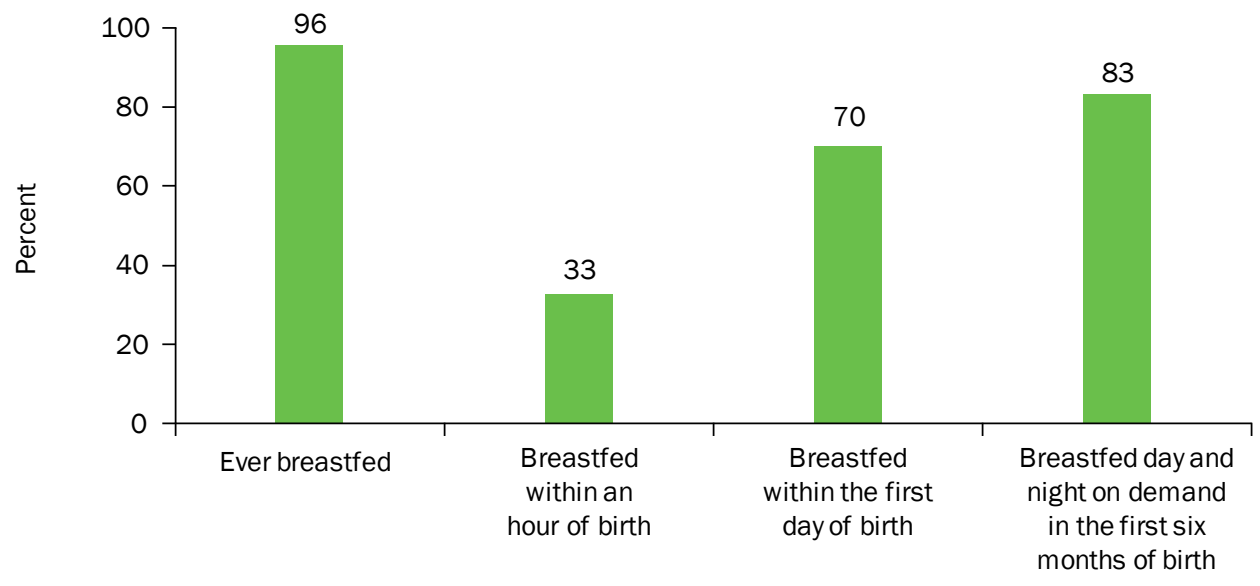

Note: ${ }^{*}$ Of married older girls who had at least one live birth.

\section{Reach of programmes to promote maternal, newborn and child health}

The reach of various schemes to promote maternal, newborn, and child health- the Janani Surksha Yojana (JSY), the Janani-Shishu Surakshya Karyakram, and the Integrated Child Development Services (ICDS)-was far from satisfactory. Just 32 percent of married girls with at least one live birth had received JSY cash benefits for their first birth; even among those who had given birth in a public sector facility, only 61 percent had received the cash benefits. Among married girls whose first birth took place in a public or private health facility, 54 percent reported that they had received at least one benefit dispensed under the Janani-Shishu Surakshya Karyakram. The reach of services through the ICDS programme was even more limited during pregnancy and the period of lactation. Just 33 percent of married girls reported that they had received food supplementation during pregnancy or the lactation period with respect to their first child, and fewer married girls reported that they had received health and/or nutrition education (23\%). Infant and child health services in contrast were more likely to have been accessed by married girls who had at least one child-53 percent of married girls reported that they had received various services for their first child under six years of age.

\section{Sexual health concerns and health-seeking behaviours}

Significant minorities of adolescents reported that they had experienced sexual and reproductive health problems in the months preceding the interview we had conducted. Specifically, 16-28 percent of boys and 10-38 percent of girls reported symptoms suggestive of genital infection during the three months preceding the interview. Moreover, seven percent of younger girls and 11 percent of unmarried and married older girls who had begun menstruating had experienced menstrual problems during the same reference period.

Menstrual hygiene practices were far from satisfactory, as measured by the use of sanitary napkins. Of those who had begun menstruating, 30-35 percent reported that they used sanitary napkins, 42-50 percent reported that they used pieces of cloth, and 16-25 percent reported that they used both. Those who reported using materials other than sanitary napkins cited lack of affordability, difficulty in obtaining sanitary napkins, and lack of awareness about sanitary napkins as the main reasons for not using sanitary napkins.

Health-seeking practices for sexual and reproductive health problems among adolescents were compromised among many. Only about two-thirds of boys and between one-quarter and less than one-half of girls who had experienced symptoms suggestive of genital infection in the three months prior to the interview had sought treatment for such symptoms. Likewise, among older girls who had experienced menstrual problems in the three months prior to the interview, just 31 percent of unmarried girls and 37 percent of married girls had sought treatment. Adolescents who 
had sought care did so from a range of providers, including private sector providers, public sector providers, medical shops/chemists, and unqualified providers.

Findings suggest that older adolescents (younger adolescents were not asked these questions) were shy about seeking sexual and reproductive health services. Many older adolescents-more girls than boys and more married than unmarried older girls-reported that they would indeed hesitate to approach a healthcare provider (38\% of boys and $42-62 \%$ of girls) or a pharmacy/medical shop ( $24 \%$ of boys and $44-69 \%$ of girls) for contraceptive supplies.

\section{Mental health concerns}

As far as the mental health status of adolescents is concerned, findings show that while the majority (90-97\% of boys and $72-95 \%$ of girls) did not display any symptoms suggestive of mental health problems, considerable proportions displayed symptoms of depression, which more girls than boys, particularly unmarried and married older girls, had done so. Specifically, four percent of younger boys and eight percent of older boys displayed signs of mild depressive disorders (a score of 5-9 on the PHQ-9 scale) in the two weeks prior to the interview as did five percent of younger girls, 12 percent of unmarried older girls, and 19 percent of married older girls. Hardly any younger adolescents displayed symptoms of moderate to severe depressive disorders (a score of $10-27-0.1 \%$ of boys and $0.9 \%$ of girls), but two percent of older boys, five percent of unmarried older girls, and nine percent of married older girls displayed moderate to severe depressive disorders during the two weeks prior to the interview. Moreover, one percent of younger boys and two percent of younger girls in ages 13-14 had seriously contemplated committing suicide in the year preceding the interview. Among older adolescents, three percent of boys, five percent of unmarried girls, and nine percent of married girls reported suicidal tendencies; less than one percent of boys and 1-2 percent of unmarried and married girls had made at least one attempt to commit suicide. Findings also show that a small minority of all adolescents-4-6 percent of boys and 3-7 percent of girls-had inflicted such acts of self-harm as cutting or biting themselves, pulling their hair, and banging their head against something or hitting themselves.

\section{Injuries}

Notable proportions of adolescents, particularly boys, had experienced injuries in a road accident or in other circumstances during the three months prior to the interview (Figure 18). Among boys, for example, 8-9 percent of boys and 2-4 percent of girls were injured in a road accident. Larger proportions of adolescents reported experiences of injury in other circumstances (19-26\% of boys and $9-17 \%$ of girls). On the whole, 33 percent of younger boys and 25 percent of older boys reported at least one injury in the three months prior to the interview as did 19 percent of younger girls, 15 percent of unmarried older girls, and 10 percent of married older girls.

Figure 18: Percentage of adolescents reporting experiences of injuries in the three months prior to the interview, Uttar Pradesh, 2015-16

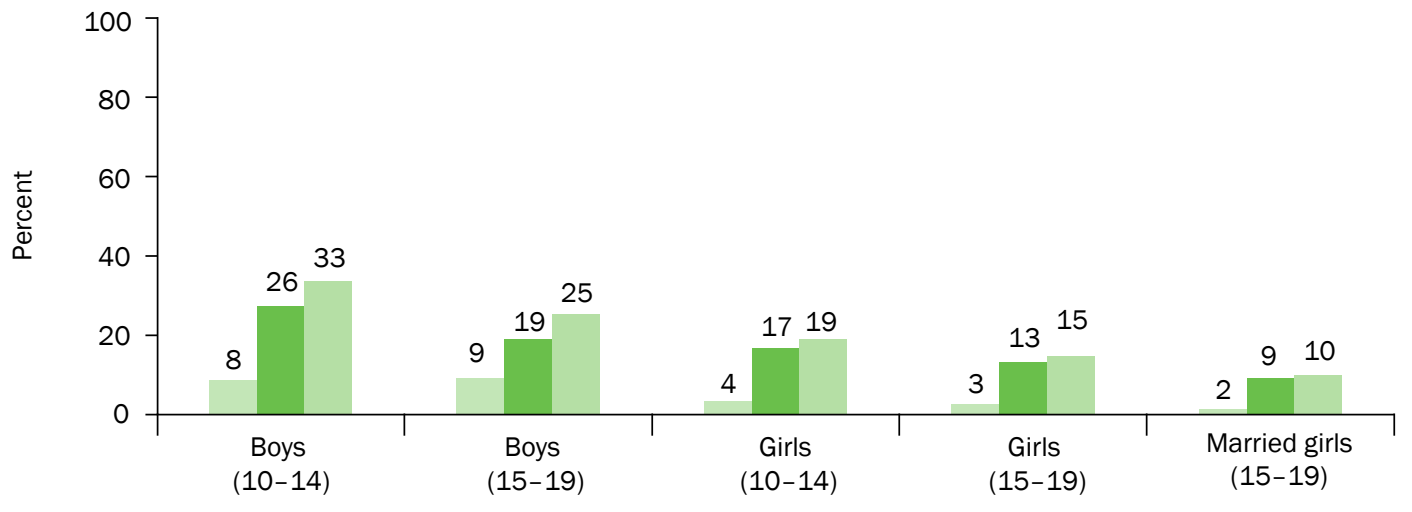

$\square$ Injured in a road accident $\square$ Injured in other circumstances (fight, fall, animal bite, etc.) $\square$ At least one injury 


\section{Substance use}

Findings show that a substantial proportion of older boys and a small minority of younger adolescents and unmarried and married older girls reported the consumption of tobacco and alcohol. Four percent of younger boys and 22 percent of older boys had ever consumed tobacco products as had less than one percent of younger girls and 2-5 percent of unmarried and married older girls; most boys and girls who had ever consumed tobacco products had done so once a week or more frequently in the month prior to the interview. Seven percent of older boys and hardly any in the other four categories of adolescents had ever consumed alcohol. Hardly any boys (less than 1\%) and not a single girl reported drug use.

\section{Engagement in physical activities}

Between three-quarters and nine-tenths of boys were typically engaged in sports and games or other physical activities. Fewer girls, particularly unmarried and married older girls, however, reported engagement in sports and physical activities-70 percent of younger girls, 40 percent of unmarried older girls, and 12 percent of married older girls. The majority of boys (both groups) and younger girls who were usually engaged in sports and games or other physical activities had engaged in such activities several times a week in the month preceding the interview. A considerably smaller proportion of unmarried and married older girls reported such engagement. Indeed, 13 percent of unmarried older girls and 37 percent of married older girls reported that they had not played any sports and games or engaged in other physical activities in the month preceding the interview.

\section{Awareness and reach of programmes that impart health information to adolescents and meet their health needs}

Findings also highlight the limited awareness and reach of government programmes intended to impart health information to adolescents and to meet their health needs. We explored adolescents' awareness of the Rashtriya Kishor Swasthya Karyakram by asking about their awareness of peer educator programmes implemented by RKSK. Findings show that 1-3 percent of boys and 1-5 percent of girls had heard about any peer education programme, with little differences by residence in rural or urban areas in the proportions of boys and girls who reported awareness of such programmes. However, we cannot rule out the possibility that these respondents could have been referred to the peer education programmes of non-governmental organisations. The reach of health programmes in schools and colleges in the year preceding the interview was limited-14-17 percent of boys and 9-20 percent of girls who were enrolled in school or college at the time of the interview reported that they had received health-related information or services from a healthcare provider in their school/college.

Findings show that frontline workers (FLWs), namely, accredited social health activists (ASHAs) and anganwadi workers (AWWs) were widely known to adolescents. Among boys, 82-91 percent and, among girls, 84-93 percent, for example, had heard about AWWs. Fewer adolescents had heard about ASHAs-55-74 percent of boys and 60-86 percent of girls. However, adolescents' interactions with AWWs and ASHAs in the year preceding the interview were limited, with the exception of married older girls. Some 10-11 percent of younger boys and girls had received healthrelated information or services from FLWs in the year preceding the interview as had three percent of older boys and eight percent of unmarried older girls. A much larger proportion of married older girls had received information on services from FLWs during the same reference period (31\%).

Findings also show that among older adolescent girls who had interacted with ASHAs or AWWs, married girls were almost twice as likely as their unmarried counterparts to have received health information from them. Unmarried older girls typically received general health and hygiene-related information, while married older girls typically received sexual and reproductive health information, followed by nutrition-related information. Sexual and reproductive health information imparted to unmarried older girls focused mainly on physical changes during adolescence, which was most likely to be on menstruation, while it comprised information related to pregnancy-related care and immunisation and newborn care practices for married older girls. Information on contraception and safe sex was rarely recalled even by married older girls.

While married older girls were more likely than the unmarried older girls to have received information from an ASHA or AWW in the year preceding the interview, a larger proportion of unmarried than married older girls reported that they had received health services from them. 
Health services that unmarried older girls received from ASHAs typically comprised iron and folic acid supplements or deworming tablets and sanitary napkins. AWWs dispensed iron and folic acid supplements or deworming tablets, provided nutritional supplementation, and gave health check-ups, which were most likely restricted to the measurement of height and weight. Services received by married older girls from an ASHA comprised escorting them to a health facility, facilitating their health check-ups, and providing them iron and folic acid supplements, while AWWs provided nutritional supplementation and facilitated health check-ups. None of the unmarried older girls and just one percent of married older girls reported that they had received condoms or oral pills from an ASHA or AWW.

Hardly any adolescents had heard about adolescent friendly health clinics (1-3\% of boys and $2-5 \%$ of girls) or had received services from adolescent friendly health clinics in the year preceding the interview $(0.2 \%$ or fewer).

Awareness of the sanitary napkin distribution programme among girls who had begun menstruating was limited; 23 percent of younger girls and 36-39 percent of unmarried and married older girls were aware of it (Figure 19). Only a negligible minority of girls who had begun menstruating reported that they had received sanitary napkins through schools or from community-level health workers in the year preceding the interview (3-4\%).

Figure 19: Awareness and reach of sanitary napkin distribution scheme among girls who had begun menstruating, Uttar Pradesh, 2015-16

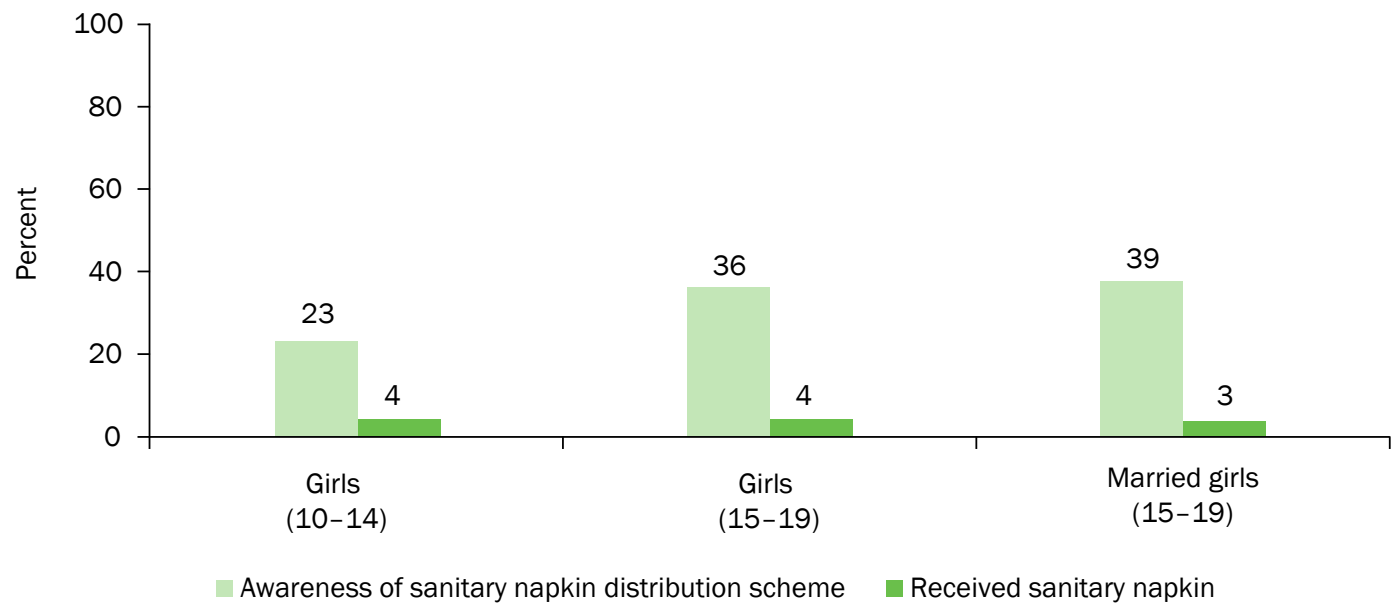

Awareness of village health and nutrition days (VHNDs) among rural adolescents was also limited-25-37 percent of boys and 30-59 percent of girls reported awareness (Figure 20). Far fewer-three percent of boys and 2-16 percent of girls had attended a VHND in the year preceding the interview.

Figure 20: Awareness of and attendance at village health and nutrition days, * rural Uttar Pradesh, 2015-16

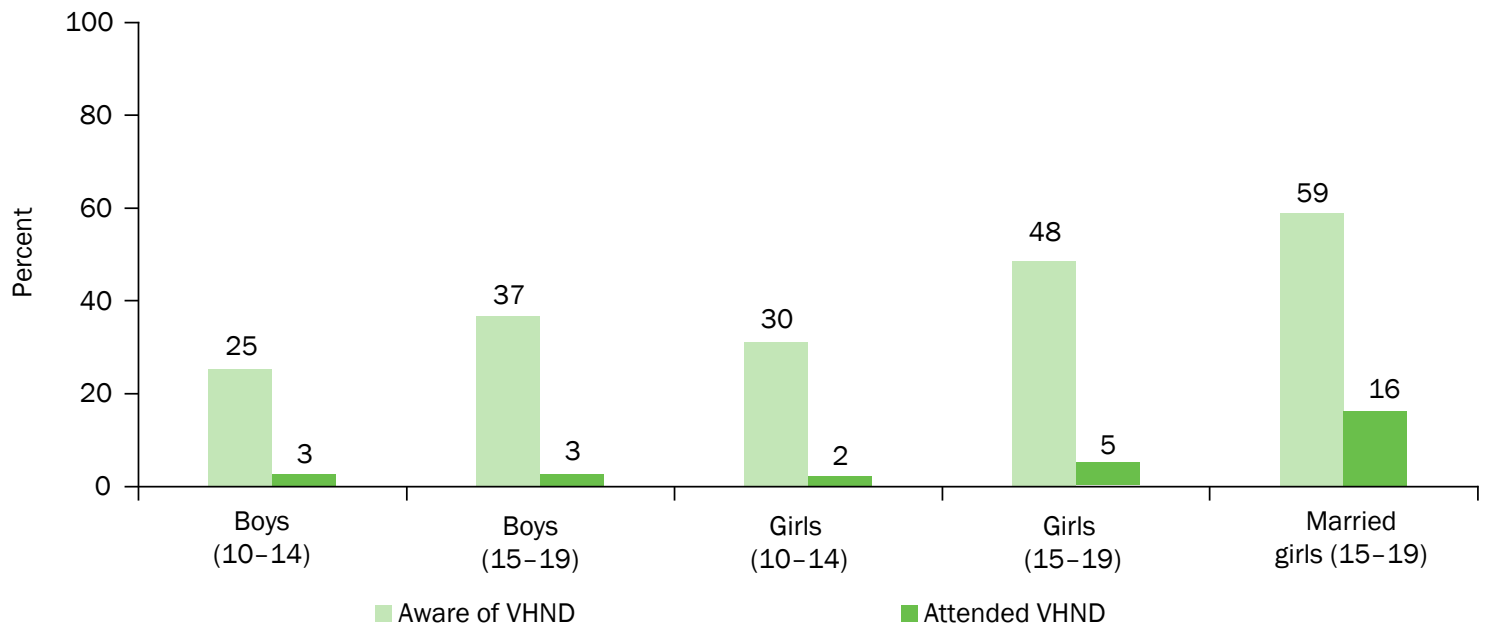

Note: *This question was asked for rural respondents only. 


\section{Dietary practices and nutritional status}

Findings confirm the poor dietary practices of adolescents. The only item prescribed in the balanced diet for adolescents and probed in the study that was consumed daily by the vast majority of adolescents was vegetables other than dark green leafy vegetables ( $76-78 \%$ of boys and $82-85 \%$ of girls). No more than half of the boys and two-fifths of the girls daily consumed most of the other food items. Even weekly consumption of several of these items was not common.

Notable proportions of adolescents, particularly younger adolescents and boys were thin-30 percent and 20 percent of younger and older boys, respectively, and 20 percent of younger girls and 11 percent each of unmarried and married older girls. Some 6-8 percent of boys and 1-4 percent of girls were severely thin. Findings also show that three percent of boys and 4-5 percent of girls were overweight or obese. Moreover, 33-37 percent of boys and 54-66 percent of girls were anaemic (Figure 21). Specifically, 29 percent of younger boys and 19 percent of older boys were mildly anaemic as were 37-44 percent of girls. Some 8-12 percent of boys were moderately anaemic as were 13 percent of younger girls and 19-25 percent of unmarried and married older girls. Finally, one percent or fewer boys and 2-4 percent of girls were severely anaemic.

\section{Figure 21: Percentage of adolescents who were anaemic, Uttar Pradesh, 2015-16}

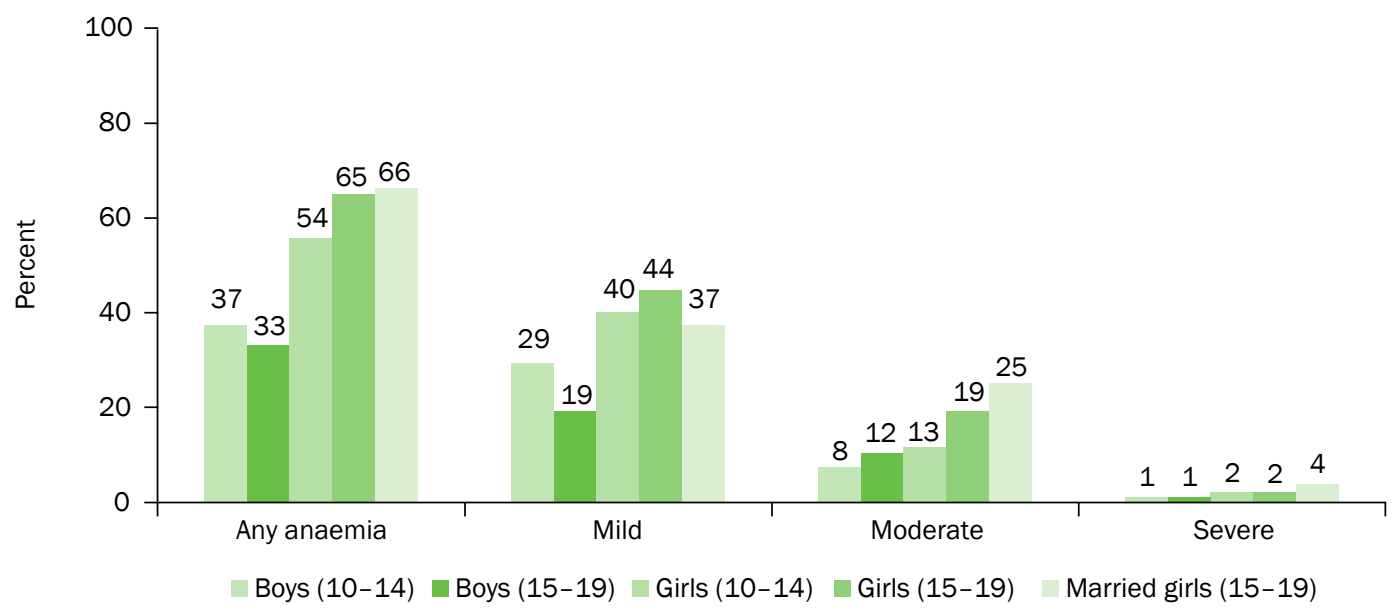

\section{Awareness and reach of government programmes intended to improve nutritional status of adolescents}

Findings also highlight the limited awareness and reach of government programmes intended to improve the nutritional status of adolescents in the state. Awareness of the weekly iron and folic acid supplementation (WIFS) programme was limited-33 percent of younger girls compared with 26 percent of younger boys and 35-36 percent of unmarried and married older girls compared with 25 percent of older boys were aware of it. Even fewer had received iron and folic acid tablets (7-8 percent of younger adolescents and 3-5 percent of older adolescents) or deworming tablets (nine percent of younger adolescents and 2-6 percent of older adolescents) from the WIFS programme in the year preceding the interview. On the whole, 13-14 percent of younger adolescents and 5-9 percent of older adolescents had received at least one of these tablets in the year preceding the interview. Among those who had received iron and folic acid tablets in the year preceding the interview, few had consumed these tablets weekly, as prescribed, in the month preceding the interview-just 4-6 percent of boys and 8-14 percent of girls. Among those who had received deworming tablets in the year preceding the interview, 61 percent of younger boys and 51 percent of older boys had consumed deworming tablets in the six months prior to the interview as had 63 percent of younger girls, 51 percent of unmarried older girls, and 47 percent of married older girls.

Hardly any adolescents had undergone anaemia testing in their school or at the anganwadi centre in the year preceding the interview-1-2 percent of boys and 2-5 percent of girls. Somewhat larger proportions of adolescents reported that their weight had been checked in the year preceding the interview-16-17 percent of younger adolescents and 7-8 percent of older adolescents. Similarly, 11-14 percent of younger adolescents and 2-6 percent 
of older adolescents reported that their height had been checked in the year preceding the interview. The reach of the scheme to provide rations or a hot cooked meal from the anganwadi centre was also limited-just 6-7 percent of younger adolescents had received it in the year preceding the interview as had less than one percent of older boys, two percent of unmarried older girls, and nine percent of married girls.

\section{Participation in political activities and adherence to prosocial values and}

\section{practices}

Findings highlight that although the majority of older adolescents held positive perceptions about political processes, their participation in political activities and voting was somewhat limited. While most adolescents (75-93\%) perceived that one could vote freely and without fear and pressure, as many as 53-60 percent reported disillusionment with the commitment of political parties to work for change at the community level. Findings also confirm that, among older adolescents, membership in political parties was low (2-8\%). Further, voting behaviour of adolescents was far from universal. Among adolescents in ages 18-19 who were eligible to vote in the last election, only 46 percent of boys, 31 percent of unmarried girls, and 39 percent of married girls had cast their vote in the most recent election.

By and large, older adolescents reported prosocial attitudes-74-95 percent reported that they mixed freely with individuals of different castes, and 66-91 percent reported that they mixed freely with individuals of different religions (Figure 22). However, somewhat fewer reported that they would eat with a person of different caste or religion (50-67\%).

Figure 22: Percentage of adolescents in ages 15-19 who expressed prosocial attitudes, Uttar Pradesh, 2015-16

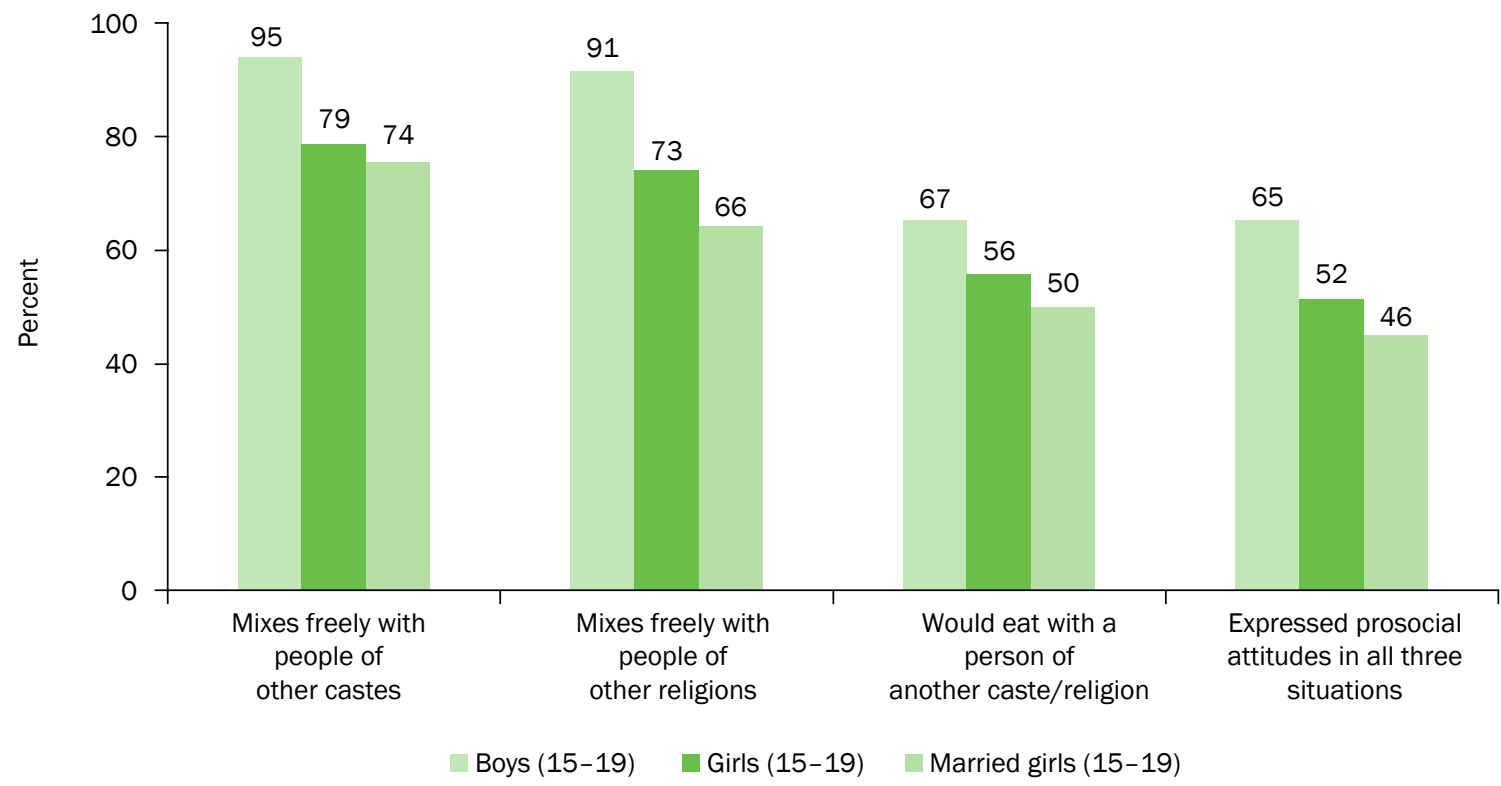

Resorting to violence to resolve conflicts was justified by many adolescents of both age groups-45-47 percent of boys and 29-38 percent of girls found the use of violence acceptable in both situations posed to them, that is, if someone showed disrespect to a female family member and if someone showed disrespect to respondent's religion.

Findings show that substantial proportions of adolescents of both age groups, particularly boys, had engaged in bullying and other antisocial behaviours. Thus, 45 percent of younger boys and 27 percent of older boys reported involvement in physical fights with other boys or men in the year preceding the interview as did 30 percent of younger girls and 2-10 percent of unmarried and married older girls with other girls or women. As many as 24-25 percent of younger boys and girls had bullied a boy/girl who was younger or weaker than them in the 12 months preceding the interview as had 18 percent of older boys and 2-10 percent of unmarried and married older girls. Findings also show that two percent of younger and older boys had robbed someone in the year preceding the interview. Finally, 
one percent of older boys acknowledged that a boy in their family, their friends, or a boy in their village/ward had ever threatened to throw/had thrown acid on a girl or woman. Similarly, one percent of younger girls and 3-4 percent of unmarried and married older girls reported that someone had ever threatened to throw/had thrown acid on them or their acquaintances (a girl in their family, friends, a girl in their village).

Findings show that markers of trafficking for labour or commercial sexual exploitation were not unknown to adolescents, and that boys were more likely than girls to report work-related markers of trafficking (false promises of a good job), while girls were more likely than boys to report marriage-related markers (false promises of a marriage or proposals for marriage with grooms outside the state). One percent of younger boys and five percent of older boys reported some familiarity with work-related markers of trafficking. None of the younger girls and 1-2 percent of unmarried and married older girls reported so. In total, 1-3 percent of boys and 3-12 percent of girls acknowledged some familiarity with marriage-related markers of trafficking.

\section{Recommendations for programmes}

The findings of UDAYA show that adolescents are a heterogeneous group with correspondingly diverse needs and that they face numerous challenges in making the transition to adulthood. We identify and discuss in this chapter several programmatic areas for action to improve the situation of adolescents.

\section{Universalise quality secondary education attainment}

Although school enrollment was nearly universal, attainment of educational milestones was far from universal. Concerted efforts are needed if the country is to achieve the Sustainable Development Goal 4 of the United Nations development agenda that seeks to promote learning opportunities universally and ensure quality education that is inclusive and equitable. The government has articulated its commitment to improving the schooling situation in the country, as can be seen in the Right of Children to Free and Compulsory Education Act, 2009, the draft National Educational Policy 2016, and several programmes, such as the Sarva Shiksha Abhiyan and the Rashtriya Madhyamik Shiksha Abhiyan. What is needed is a strong commitment to ensure that these programmes are effectively implemented and that these do indeed reach the most disadvantaged groups. Our theoretical framework, outlined in Chapter 1, identified the attainment of at least a quality secondary education as a key indicator of a successful transition to adulthood, and our findings highlight several areas in need of attention.

\subsection{Support adolescents to complete a secondary education}

Evidence from UDAYA shows that school completion rates were low-among adolescents in ages 18-19, only threefifths of boys and unmarried girls and one-third of married girls had completed high school (Class 10). Several factors inhibited school completion; leading reasons among boys were lack of interest in studies, economic constraints, and poor quality of facilities and teaching; and, among girls, they were parental perceptions that education is not necessary, economic constraints, housework-related reasons, distant location of the school, and non-availability of transportation. UDAYA findings concur with evidence synthesised in a recent review of promising models for supporting adolescents' transitions to adulthood (Jejeebhoy, 2017), and as recommended in the synthesis, multiple initiatives are needed to remove these barriers to educational opportunities and to foreground the relevance of a secondary education among both adolescents themselves and their parents and communities.

At the adolescent level, programmes and approaches must pay attention to adolescents' lack of interest in schooling. Strategies are needed to create positive peer support and establish norms that encourage school completion. They also need to create a school climate where adolescents feel connected, particularly among those who display lack of interest. Furthermore, there is a need to incorporate skill-building models for livelihood opportunities within the school setting that will not only raise adolescents' aspirations regarding their education and careers, but also provide them opportunities to gain market-driven job skills. These approaches will go a long way in assuring adolescents about the relevance of a secondary education, on the one hand, and encouraging interest in studies on the other.

At the parent and family level, programmes are needed that promote positive attitudes towards education and school completion, demonstrate to parents the relevance of the curriculum for future opportunities for both their sons 
and daughters, raise their aspirations for their children, and encourage greater parental involvement in children's education, particularly with regard to adolescent daughters. Campaigns like the Beti Bachao Beti Padhao need to be delivered using multiple channels and formats to achieve saturation and impact.

Economic pressures that dissuade parents from enrolling their children in school and from keeping them in school once enrolled need to be addressed. There are several on-going central- and state-sponsored programmes that aim to reduce the cost of education in the form of conditional and unconditional cash transfers as well as provision of free tuition, scholarships, school uniforms, books, and supplies (Jejeebhoy, 2017). Evaluations of these programmes, for example, the Dhanalakshmi scheme and Apni Beti Apna Dhan, have shown that these schemes have had promising outcomes, at least as seen in the increased retention of girls in primary schools (Sekher and Ram, 2015; Nanda et al., 2016). Findings from UDAYA show that most adolescents in the state who were enrolled at the time of the interview or in the year preceding the interview in a class whose students were eligible for entitlements from their school were aware of such entitlements as midday meals, uniforms, textbooks, and scholarships; however, proportions of adolescents who had benefited from these entitlements varied. It is important, therefore, to ensure that these government programmes do indeed reach the most disadvantaged groups of adolescents enrolled in both government and private schools. Our findings that, despite these programmes, economic pressures had prevented many adolescents from completing a secondary education call for, as advocated by many others, restructuring the incentives, modifying conditionalities, simplifying procedures, and, more importantly, adopting targeted approaches to include the poorest and most socially disadvantaged households (Sekher and Ram, 2015; Nanda et al., 2016). Findings also emphasise the need for further research to better understand what economic incentives will work to retain the most vulnerable in school and enable them to complete a secondary education.

Efforts must also be made to remove school-level barriers, particularly to promote secondary school completion among girls. Poor infrastructure and amenities, indifferent quality of education, and, for girls, distant location of the schools are key school-level barriers identified by adolescents. While it may not be practical to have a secondary school in every village, it is important to ensure safe transportation to school for girls. Several state governments have launched various schemes to remove these barriers (for example, the bicycle scheme for girls in Jharkhand, Bihar, and elsewhere); the evaluation of the bicycle scheme to facilitate safe transport in states like Bihar and Jharkhand has shown that it has contributed to increasing age-appropriate enrolment in secondary schools among girls (Muralidharan and Prakash, 2017). At the same time, schools must take note of and address the concerns of the large number of adolescents who drop out because of lack of interest, failure in their examinations, poor quality teaching, the lack of female teachers, or the paucity of amenities. Finally, given the large proportions reporting that schooling had been interrupted because they were required for house work or work on the family farm or business, and given the reality of adolescents' lives and the economic pressures on families, efforts need to be made to adjust school timings, including the establishment of evening schools, to enable children to accommodate work on the family farm or business without sacrificing their education.

\subsection{Expand 'second-chance' programmes}

According to our findings, one-fifth of married older girls were never enrolled in school and among older adolescents who were ever enrolled in school, 27 percent of boys, 33 percent of unmarried girls and 73 percent of married girls had discontinued schooling before completing Class 12. This calls for creating 'second-chance' programmes for adolescents who had missed the opportunity to acquire an adequate level of formal education. Our findings lend support to this idea, as one-fifth to one-third of older adolescents who were never enrolled in school and one-quarter to two-fifths of older adolescents who had discontinued schooling had expressed a desire to get enrolled or return to school. 'Second-chance' programmes are already being run by some NGOs such as Pratham and the MV Foundation, and these may be suitably modified at scale.

\subsection{Invest in improving learning outcomes}

Concerted efforts to improve learning outcomes are needed, as evident from our findings: just three-quarters of older boys and unmarried older girls and half of married older girls could read a Class 2 text fluently in Hindi; fewer than half of older boys and one-tenth to one-quarter of unmarried and married older girls could solve a simple division problem; not all adolescents who had completed even primary education (that is, Class 8 or more) could read a Class 2 text fluently or solve a simple division problem; and adolescents tended to lose literacy and numeracy skills over 
time. Indeed, the Government of India has articulated its commitment to improving learning outcomes in several policies and programmes, including the National Policy on Education 1986, the Programme of Action 1992, and the draft National Education Policy 2016 (Ministry of Human Resource Development, Government of India, 2016). Moreover, the government has recently amended the Central Rules of the Right of Children to Free and Compulsory Education (RTE) Act, 2009, to include class-wise and subject-wise learning outcomes for all elementary classes and to link the achievement of learning outcomes with continuous and comprehensive evaluation (Ministry of Human Resource Development, 2017a). What is needed is a strong commitment to ensure that these policies and programmes are effectively implemented and that they reach the most disadvantaged groups.

Several intervention models have been pilot tested in India to improve learning outcomes, and these have identified a number of strategies that hold promise; for example, adapting curriculum to children's learning levels and providing level-appropriate learning materials instead of grade-level curriculum (Banerjee et al., 2016); providing remedial education by informal teachers hired from the community (Banerjee et al., 2007) or by community volunteers (Lakshminarayana et al., 2013); providing additional teachers (Chin, 2005; Muralidharan and Sundararaman, 2013); providing incentive payments to teachers based on improvement in their students' test scores (Muralidharan and Sundararaman, 2011); information and communication technology (ICT) based instruction (Linden, 2008); and engaging parents and school management committees to bring accountability in secondary education for girls (Santhya et al., 2016). Investments are also required to adapt, re-evaluate, and upscale these promising models.

\subsection{Target first-generation learners}

Our findings highlight that the first-generation learners have a long way to catch up in secondary school completion and learning outcomes. Older adolescents whose mother was uneducated or poorly educated were less likely to have completed secondary school than those whose mother was better educated; learning outcomes likewise improved steadily with the mother's level of education attained. Programmes that seek to improve enrolment in secondary schools, ensure secondary education completion, and enhance learning outcomes, targeted at adolescents and their parents/families, should be specially targeted toward first-generation learners.

\subsection{Build teacher capacity}

Findings that that many adolescents relied on private tuition, and that learning outcomes remain poor even among those who had completed primary education highlight the need for focusing on providing better training to teachers and ensuring accountability from them. It is to be noted that efforts in this direction have been initiated by the Government of India (Ministry of Human Resource Development, 2017b). Teachers need to be aware that many students are first-time learners with parents who have never been to school or have only modest levels of education; they should be made aware that reasons for dropping out of school, such as lack of interest, may at least partly be attributed to their own failure to communicate the curriculum; and they need to be trained to make instruction more stimulating and adolescent friendly. Further, they need to be held accountable for the performance of their students. Promising evidence from a programme that provided incentive payments to teachers based on the average improvement of their students' test scores (Muralidharan and Sundararaman, 2011) needs to be reviewed and considered for replication.

\section{Prepare adolescents for skilled employment}

The National Policy on Skill Development and Entrepreneurship (Ministry of Skill Development and Entrepreneurship, 2015) places emphasis on the need for a skilled workforce, and, towards this objective, the National Skill Development Mission aims to skill or upgrade the skills of 150 million people, mostly youth, by 2022. Indeed, a transition into productive work roles at appropriate ages is a key indicator of a successful transition to adulthood, and our findings highlight that in order for adolescents to make this transition and for the Skill Mission to achieve its goal, several challenges will need to be overcome. 


\subsection{Strengthen efforts to prevent child labour}

Findings show that 7-10 percent of adolescents were initiated paid work in childhood (before age 14), and this reinforces the recommendation highlighted earlier on the need to provide conditional grants and targeted subsidies to disadvantaged groups in order to encourage parents to opt for schooling instead of work for their children. At the same time, it is important to vigorously enforce existing laws that prohibit child labour.

\subsection{Enhance skills to improve employment potential}

Findings suggest that significant proportions of adolescents are not employable, as they lack adequate skills. As mentioned above, not all older adolescents had completed a secondary school education, and reading and mathematics skills were generally limited. Moreover, just six percent of older boys and 12-15 percent of unmarried and married older girls had attended a formal vocational training programme. Even among adolescents who had attended a vocational training programme, exposure to marketable skills was limited, especially among girls. While considerable proportions of boys reported exposure to computer skills, girls tended to opt for relatively traditional vocational skills and may not have had the opportunity to learn about market needs or to develop appropriate skills for which a demand exists. It is also notable that those who were engaged in paid work were working largely as agricultural and unskilled non-agricultural labourers. Considerable proportions of adolescents, particularly those who had completed 12 or more years of schooling, were actively seeking employment, which suggests a possible disconnect between adolescent skills and market needs.

The state needs to significantly strengthen investments in programmes that enable adolescents to make a successful transition to work roles. Enhancing employment potential would depend to a considerable extent on improvements in educational attainment, discussed above, and also on greater investment towards enabling adolescents to acquire vocational skills. There exists a considerable unmet need among older adolescents for vocational training programmes: 11 percent of boys and 29-34 percent of girls had wanted to attend a training programme but had been unable to do so, largely for such demand-side reasons as constraints in affording the cost of the course, unsuitable course timings, and objections from their family, and such supply-side reasons as the paucity of training centres and lack of awareness about these centres and their locations.

Formal mechanisms need to be developed that provide opportunities for potential employers to partner with schools and vocational institutions to increase adolescents' exposure to the world of work, including an understanding of the jobs available in the local economy, avenues for pursuing those jobs, and skills and experience necessary for obtaining them. Efforts are also needed to offer demand-driven training-to-employment programmes that focus intensively on the requirements of specific available jobs and include a post-training placement component. There is also a need to promote a more positive image for vocational education. The Uttar Pradesh Skill Development Mission is a step in the right direction; however, just one-fifth of older boys and between one-quarter and one-third of unmarried and married older girls had heard about it, and even fewer were aware of any vocational training centres that offer training under this mission-just eight percent of older boys and 5-8 percent of unmarried and married older girls. It is important that this initiative is popularised more vigorously and centres that offer vocational skills training under the mission are expanded. Efforts are needed to bridge the gap between the huge demand that adolescents have for acquiring livelihood skills and their access to available entitlements through which to acquire these skills.

The mere availability of skill-building programmes is not sufficient, particularly for girls. Adolescents need to be made aware of the range of training programmes available and need to be counselled about skills for which there is a market demand. Further, trained adolescents require support in accessing apprenticeship or employment opportunities and in overcoming challenges that may inhibit their availing of opportunities, such as parental disapproval, transportation concerns, and so on.

Efforts are required to create alternative models to traditional training institutes, such as mobile camps, community colleges, and courses on vocational skills in high schools. Attention needs to be drawn to improving the quality of 
vocational skills training programmes, updating curricula based on emerging industry requirements, improving the quality of trainers, and increasing the focus on soft skills, including how to prepare curriculum vitae and present oneself at interviews.

Evaluation of the effect of skilling programmes on adolescents and young people are sparse in India (Jejeebhoy, 2017). Existing programmes implemented by government and civil society partners that are aimed at job creation need to be evaluated, so that their reach and impact in enabling adolescents and youth to make a successful transition to work roles may be assessed. Evaluation findings will provide evidence for the upscaling of successful models or for the revamping of existing programmes based on lessons learned.

\section{Empower adolescents and establish egalitarian norms}

The markers of a successful transition to adulthood also include the ability of adolescents to navigate this transition in an informed and equitable manner, that is, to make informed choices and hold equitable notions of masculinity and femininity. Several programmes have been implemented-for example, SABLA/Kishori Shakti Yojana (KSY), the Nehru Yuva Kendra Sangathan (NYKS) youth club movement, and the Beti Bachao Beti Padhao programmethat focus on building girls' agency, on the one hand, and changing notions of male superiority and female submissiveness, on the other. However, findings highlight the persisting limited agency of adolescents and the striking gender divide in all dimensions of adolescents' agency. Although adolescent girls were far more disadvantaged than adolescent boys, many boys were also not able to exercise agency in their everyday lives. Adherence to gender egalitarian attitudes was limited. Action to reverse this situation needs to be prioritised.

\subsection{Promote gender transformative life skills programmes for boys and girls}

Evidence shows that adolescents in Uttar Pradesh have limited agency and many hold gender in egalitarian attitudes about masculinity and femininity-for example, while 97 percent of older boys were free to visit various places unescorted, just 38 percent of unmarried older girls and 13 percent of married older girls were accorded such liberty. Control over money was also limited and gendered-while similar proportions of older boys and unmarried older girls owned a savings account (45-46\%), 83 percent of boys who owned an account compared with 69 percent of girls operated the account themselves. Boys were more likely than girls to meet their friends frequently, and far more likely to meet them in venues outside the home, school, and those related to their daily chores. Egalitarian gender role attitudes were held, moreover, by just half of younger boys, about three-quarters of older boys, younger girls, and unmarried older girls, and two-thirds of married older girls.

Findings call for the promotion of gender transformative life skills programmes for adolescent boys and girls that will not only raise their awareness of new ideas and the world around them, but also enable them to put information into practice, encourage them to question gender stereotypes and promote new concepts of masculinity and femininity, develop self-esteem, and strengthen their skills in problem-solving, decision-making, communication, and interpersonal relations and negotiation. Given girls' limited mobility and opportunities to build/nurture supportive friendships, it is important that girls are offered a safe space in which to gather and develop strong support systems.

An increasing number of intervention models to build agency and promote egalitarian gender role attitudes among adolescents have been tested in India (Acharya et al., 2009; Achyut et al., 2011; Das et al., 2012; Jejeebhoy et al., 2017a; Mehra et al., 2016; Verma et al., 2006). As noted in a recent synthesis of promising interventions (Jejeebhoy, 2017), these models could be reviewed and replicated or scaled-up as appropriate. The potential that programmes (such as the Rashtriya Kishor Swasthya Karyakram of the Ministry of Health and Family Welfare, SABLA and Kishori Shakti Yojana of the Ministry of Women and Child Development, and the NYKS youth club programme of the Ministry of Youth Affairs and Sports) hold for scaling-up successful lessons learned from these intervention models must be exploited to reach a critical mass of adolescents.

Programmes to promote gender equitable norms and practices among adolescents must also target parents and other adults who influence and control the lives of adolescents for the latter to benefit from such programmes. These influential adults need to be sensitised to equitable gender norms and thereby persuaded to adopt new notions about gender and egalitarian socialisation practices for boys and girls. 
All programmes to which adolescents are exposed need to be viewed and structured through a gender lens. School textbooks need to be evaluated as a medium to introduce ideas that promote gender equity. Teachers and healthcare providers require sensitisation about gender inegalitarian attitudes and girls' limited agency and orientation about ways of redressing these imbalances. Teachers, in particular, need training to ensure that classroom interaction does not inadvertently favour boys.

\subsection{Strengthen family life education for those in school and out of school}

The findings of UDAYA provide considerable evidence that family life or sex education is urgently needed among adolescents, for both those in school and those who have discontinued their education. Findings demonstrate a limited understanding of sexual and reproductive matters among adolescents, including among married older girls. Misconceptions abound on most topics: sex and pregnancy, contraceptive methods, STIs and HIV/AIDS, and maternal and newborn care practices. Where adolescents have shown awareness of sexual and reproductive health matters, many of them exhibited only superficial knowledge. While few adolescents had been exposed to family life education, key topics covered related to HIV/AIDS rather than sexual and reproductive topics more generally. Even so, those who had been exposed to such an education were more likely than those who had not been to display in-depth awareness of sexual and reproductive matters. Moreover, notable proportions of adolescents-one-tenth to two-fifths-indicated a preference for receiving information about sexual and reproductive matters from teachers, healthcare providers, or other influential adults in the community.

These findings reinforce the need to expand the content and reach of the Adolescence Education Programme (AEP). They call for a commitment to strengthen age-appropriate family life or comprehensive sexuality education for all adolescents, that is, for those in school and those out of school, those who are married and those who are unmarried, and those from rural and those from urban areas. Moreover, there is a need to expand the content of existing awareness-raising programmes to include not just HIV-related information, but broader sexual and reproductive topics. These programmes should be designed not only to raise awareness among adolescents, but also to enable adolescents to correctly understand and assess the risks they face and, thereby, to adopt appropriate protective actions. Comprehensive sexuality education should also promote gender egalitarian attitudes and empower adolescents with the communication and negotiation skills that will allow them to make informed choices and an understanding of their entitlements.

Peers have also been identified as acceptable sources of information, and while there is a debate about the effectiveness of peer educators in other settings, there is some evidence from India that suggests that young people may indeed be a reliable source of information for their peers (Pandey et al., 2016; Mehra et al., 2016; Jejeebhoy et al., 2017a). The Rashtriya Kishor Swasthya Karyakram has also advocated for a peer educator approach to inform and counsel youth, and its programmes offer a unique opportunity through which to inform and empower adolescents about sexual and reproductive matters as well as many other health-related matters that may place adolescents at risk. Efforts to identify and build the capacity of peer educators and to build networks of peer educators would be a measure towards addressing the sexual and reproductive health needs of adolescents.

While evaluations of government-initiated family life or sexuality education programmes are limited, evidence from NGO-led programmes that combine sexuality education and life skills education have shown promise not only in raising awareness of sexual and reproductive matters among adolescents, but also in helping them to adopt protective behaviours (Pandey et al., 2016; Mehra et al., 2016). Investments are also required to adapt, re-evaluate, and upscale these promising models.

\subsection{Invest in violence-prevention activities}

Violence-witnessed, experienced, and perpetrated-in public and private spaces marked the lives of many adolescents in the state. One-fifth to one-third of boys and girls with both parents alive at the time of the interview had ever witnessed incidents where their father had beaten their mother and one-third to about two-thirds of adolescents with at least one parent alive at the time of the interview reported their having been slapped or otherwise physically abused by a parent since they had turned 10 years of age. As many as 16 percent of younger girls had ever experienced teasing and verbal harassment of a sexual nature, and 2-3 percent of boys and 2-9 percent of girls had experienced unwanted sexual touch. While 3-20 percent of boys had ever verbally harassed a girl in a sexual way, five 
percent of older boys reported the perpetration of forced sex, including on their romantic partner/s. Violence within marriage-emotional, physical, or sexual-was experienced by 19-30 percent of girls who had begun cohabiting. As many as 27-45 percent of boys reported involvement in physical fights with other boys or men in the year preceding the interview; likewise, 30 percent of younger girls and 2-10 percent of unmarried and married older girls reported involvement in physical fights with other girls or women. As many as 24-25 percent of younger boys and girls had bullied a boy/girl who was younger or weaker than them in the 12 months preceding the interview as had 18 percent of older boys and 2-10 percent of unmarried and married older girls.

These findings stress the urgent need for pilot testing multi-pronged interventions to prevent violence. A WHO review of evidence on what works to prevent violence suggests that programmes should include: interventions that encourage stable and nurturing relationships between parents and children in their early years; life skills programmes that seek to build social, emotional, and behavioural competencies among adolescents and preschool enrichment programmes which provide children with academic and social skills; school- and community-based programmes to promote gender equality; interventions that challenge cultural and social norms supportive of violence; and interventions to identify victims of interpersonal violence and provide them with effective care and support (WHO, 2010). Programmes must focus on both boys and girls, and they should be tailored to address their individual needs. While evidence on workable models in these areas are lacking for the most part in India, some recent experiments focused on boys hold promise, namely, the Do Kadam programme and the Parivartan programme, both of which used gender transformative life skills education and sports coaching to impart values that encouraged adolescent boys and young men to denounce attitudes that justify violence against women and girls. A second project of the Do Kadam programme trained frontline workers to identify young women at risk of violence and link them with support services (Jejeebhoy et al., 2017a; 2017b; and Das et al., 2012). Other life skills education programmes, such as Action for Adolescent Girls by UNFPA and the Better Life Options by the Centre for Catalysing Change have included components that raise awareness among girls about protecting themselves against violence and taking action in case they experience it (CEDPA, 2006; UNFPA, 2014). Investments are required to adapt, re-evaluate, and upscale these promising models.

\section{Promote good health and informed health choices}

The National Health Policy 2017 pays special attention to adolescent health, affirming a commitment to 'pre-emptive care' as well as to school health programmes that promote health and hygiene. It calls for activities to provide sexual and reproductive health services, as well as those that address other concerns such as inadequate calorie intake, poor nutrition, and mental health problems (Ministry of Health and Family Welfare, 2017). Likewise, but more sharply focused on adolescents, the Rashtriya Kishor Swasthya Karyakram has prioritised six key concerns of adolescents that may result in ill-health during adolescence itself or that may manifest in adulthood owing to practices initiated in adolescence. They include sexual and reproductive health, nutrition, mental health, substance abuse, noncommunicable diseases, and violence. UDAYA has collected data on each of these areas, and findings underscore that many adolescents are at risk of failing to make a healthy transition into adulthood. Insights from the project suggest the need for interventions that will promote a better understanding of risks and enable adolescents to modify behaviour to reduce these risks.

\subsection{Ensure that when premarital sex takes place, it is safe and wanted}

While sexual activity is initiated within marriage for the vast majority of adolescents, findings show that a sizeable proportion of boys and girls had engaged in sex before marriage. As documented in this report, many adolescents had initiated sexual activities uninformed, which reinforces our earlier recommendation for the need to provide family life or comprehensive sexuality education to adolescents. Moreover, the findings that for many adolescents, premarital sexual experiences were unsafe and, for some, that it was unwanted call for programmes that focus on building sexual and reproductive health awareness among adolescents, on developing their skills in negotiating safe sex, and in communicating with their partners on sexual and reproductive health matters. These measures should be preferably included in the gender transformative life skills education and the comprehensive sexuality education programmes discussed earlier as well as in the community-level programmes of the Rashtriya Kishor Swasthya Karyakram. At the same time, programmes should make available appropriate family planning and infectionprevention services for unmarried adolescent boys and girls in a manner acceptable to them. 


\subsection{Translate policy commitments into effective measures to promote physical and mental health}

The National Mental Health Policy 2014 has made several promises to improve the mental health of the country's population, including that of adolescents and youth. Our findings highlight the need to put these promises into action. Disturbing minorities of adolescents in ages 15-19 displayed symptoms of depression or suicidal ideation: two percent of older boys, five percent of unmarried older girls, and nine percent of married older girls displayed moderate to severe depressive disorders during the two weeks prior to the interview and same proportions in the three categories of adolescents reported suicidal tendencies in the year preceding the interview. While very few mental health interventions for adolescents have been evaluated in India, some pilot interventions have shown promise. One such intervention is the life skills education programme for adolescents in ages 14-16 in schools in urban and rural Karnataka, which teachers had conducted over the course of a year. This programme showed that adolescents who received the intervention had improved coping skills and higher self-esteem and self-efficacy (Srikala and Kumar, 2010). Similarly, a community-based multi-component intervention aiming to address mental disorders, interpersonal violence, and substance abuse among adolescents in ages16-24 in Goa found a significant decrease in symptoms of depression and violence (Balaji et al., 2011). Small-scale studies have shown that employing lay persons in schools rather than specialised health personnel for general health promotion in resource-constrained settings is a promising alternative (Rajaraman et al., 2012; Patel et al., 2010). Investments are required to adapt, re-evaluate, and upscale these promising models. Based on studies in other countries, evidence suggests that reaching and engaging with adolescents through the internet also presents a possible avenue for exploration in India (Clarke et al., 2015).

\subsection{Promote healthy dietary practices}

Our findings confirm the poor dietary practices of adolescents. Just one percent of adolescents or fewer consumed daily the five food groups that was included in the study and recommended as part of a balanced diet. Findings show, moreover, that notable proportions of adolescent boys and girls, particularly girls, were moderately or severely anaemic. These findings highlight the need for implementing programmes to promote the intake of healthy foods. Context-specific nutrition information must be disseminated in a simple, understandable, and accessible manner to adolescents and their parents. Although there are several programmes intended to improve the nutritional status of adolescents, unfortunately, the awareness and reach of these programmes remain limited. Awareness of the weekly iron and folic acid supplementation (WIFS) programme was limited to 25-26 percent of boys and 33-36 percent of girls; even fewer had received iron and folic acid tablets (3-8\%) or deworming tablets (2-6\%) from the programme in the year preceding the interview. These findings highlight the need for revamping these programmes.

\subsection{Address other health risks}

The findings from UDAYA show that adolescents face other risks-injuries, substance abuse, and lack of exercise- and these affect boys and girls differently. Injuries in a road accident in the previous three months were experienced by almost ten percent (8-9\%) of boys but by far fewer (2-4\%) girls. Among older boys, tobacco and alcohol consumption were reported by 22 percent and seven percent, respectively. Programmes are needed specifically for boys to deter them from substance abuse and practices that have potential to cause injury (for example, motorcycle riding without helmets, physical fights). Clearly this requires the internalisation of new notions of masculinity among them and imparting of gender transformative life skills education, discussed earlier, needs to incorporate messages that will influence risk-taking behaviour change in these areas.

Lack of physical activity is notable among adolescents, and differences by gender are wide. While eight percent of younger boys and 24 percent of older boys reported no physical activity, the proportions were 30 percent, 60 percent, and 88 percent among younger girls, unmarried older girls, and married older girls, respectively. Schools would do well to encourage fitness from an early age, by providing opportunities for exercise for one hour daily among students of all ages, especially girls, and helping girls to overcome parental misgivings about their engagement in sports activities. Similarly, the SABLA and other community-level programmes for girls can also incorporate a physical activity component. 


\subsection{Sensitise and train frontline workers (FLWs) to respond to the needs of all adolescents}

Findings indicate that no more than weak links exist between adolescents and frontline workers (FLWs), namely, the accredited social health activists (ASHAs) and anganwadi workers (AWWs). Although FLWs were widely known to adolescents, just 10-11 percent of younger boys and girls, 3-8 percent of older boys and unmarried older girls, and 31 percent of married older girls had received health-related information or services from FLWs in the year preceding the interview. FLWs need to be equipped with adolescent friendly IEC (information, education, and communication) materials to serve adolescents' need for information and services and also supplies such as sanitary pads and contraceptives to meet their sexual and reproductive health needs. Familiarisation of FLWs with the referral network is imperative to link adolescents in need with higher-order facilities. They must be also made responsible for informing adolescents and their gatekeepers about services to which adolescents are entitled. The goals of training programmes for FLWs should include developing their communication skills to a much greater extent than is currently demonstrated, removing inhibitions and enabling them to overcome discomfort about disseminating information, providing counselling to adolescents, and offering referrals. Training must also build FLWs' skills with regard to addressing service needs (including the provision of condoms, for example) for all categories of adolescents in a manner that is open and non-threatening. Community-level and peer education activities introduced by the RKSK programme require, moreover, specific training for ASHAs to serve as mentors to peer educators and as mediators between adolescents and the health system. Training and sensitization programmes for FLWs must be supplemented with audio-visual aids, frequently asked questions (FAQs), and case studies that providers may keep in their possession to consult in the course of their interactions with different categories of adolescents and youth. Supportive supervision is also essential in order to support FLWs to incorporate a new set of activities and a new target group (adolescent girls and boys) into their regular responsibilities.

\section{Delay marriage and recognise the vulnerabilities of married girls}

Evidence from our findings indicates that hardly any girls (or boys) preferred to marry below age 18 and that the prevalence of child marriage has declined when compared with what was reported a decade ago in the National Family Health Survey. Even so, as many as 21 percent were married before age 18, and, irrespective of age, marriages were often arranged without consulting adolescent girls themselves. Moreover, girls rarely had an opportunity to meet their husband-to-be prior to the wedding day. Married girls are hugely vulnerable. Notable proportions of married girls experienced physical (24\%) and sexual (30\%) violence perpetrated by their husband; husband-wife communication on sexual and reproductive matters was limited (59\% had discussed the number of children to have and $24 \%$ had discussed contraception). Family pressure to bear children as soon as possible following marriage was reported by one in four girls. Despite the fact that more than two in five girls wished to delay the first pregnancy, just 16 percent had used a contraceptive in the first two years of marriage. Numerous forces work against delaying the first pregnancy-objections from the husband and other family members, lack of awareness of appropriate methods of contraception or sources for methods, limited access and method-related concerns, and the lack of attention from healthcare providers. Further, pregnancy-related care is also compromised. Although almost all girls had received at least one antenatal check-up (95\%) and most had skilled attendance at the first delivery (78\%), just 37 percent had received at least one post-partum check-up, which underscores the many missed opportunities to provide a continuum of care from maternal care to newborn care for adolescent girls. Action should be taken to address child marriage and the huge health and social vulnerabilities of married girls.

\subsection{Capitalise on adolescents' preference to delay marriage and accelerate the pace of decline in child marriage}

There is a need for a multi-pronged approach to eliminate the practice of child marriage. The disconnect between preferred and actual age at marriage calls for measures that supplement information campaigns with measures to address the underlying factors, that is, social norms and economic constraints, driving child marriage. Strategies are needed to mobilise communities to help parents resist pressures that compel the practice of child marriage. Moreover, initiatives are needed to establish new norms and practices and to actively engage influential persons in the community, including religious and political leaders, towards this end. Strategies for community mobilisation must involve adolescents as well as their families. Community-based and frontline workers must play a greater role 
in identifying girls at risk of child marriage and prevent such marriages. Messages that raise awareness on marriage laws and, in particular, the fact that the law advocates prosecution for all those who play any role in child marriage need to be disseminated.

Equally important is to ensure greater commitment from relevant authorities to enforce existing laws on the minimum age of marriage and the registration of marriages and to levy penalties on violators. Allowing for anonymous reporting, making law enforcement agencies and others aware that the practice of early marriage is not a minor violation, and making the guidelines for penalties clear to enforcement agencies and the wider community are possible steps in this direction.

Efforts to delay marriage also require providing girls with viable alternatives to marriage in the form of accessible and quality schooling, opportunities to build (and use) livelihood skills, and employment opportunities they can avail. Working with the education sector to make schooling for girls more accessible and to make classrooms gender sensitive and responsive to the needs of girls and the concerns of their parents is also important. Meaningful, affordable, and easily accessible livelihoods training to girls, within and outside the educational system, would help to expand choices for girls, instead of one that restricts them to early marriage. Furthermore, family life education and gender transformative programmes, including the Adolescence Education Programme and SABLA, must incorporate sessions to reinforce messages against child marriages and build girls' ability to negotiate when and whom they marry.Efforts to prevent child marriages should be particularly targeted at families of girls who are most at risk of discontinuing their studies before completing Class 10 and those belonging to socially and economically disadvantaged groups.

\subsection{Sensitise adolescents and parents to adolescents' right to participate in marriage-related decisions}

The failure to engage adolescents in decision-making with respect to their marriage calls for measures to sensitise parents about the need to involve their children in marriage-related decisions and also the need for adolescents to interact with their prospective spouse prior to the wedding day. It is also important to make parents aware of the physical and mental health consequences of child marriage and the adverse experiences of many girls who were married early or who were unprepared for marriage. They need to be apprised about the benefits of the participation of adolescent girls and young women in the selection of their husband for later married life.

There is also a need for expanding the policy discourse that stresses the need to raise marriage age to include ensuring, as advocated by the Convention on the Elimination of All Forms of Discrimination Against Women, the "free and full consent' of youth in the selection of their spouse.

\subsection{Address power imbalances within marriage}

Findings demonstrate that relationships within marriage remain unequal: notable proportions of married girls had experienced physical and sexual violence perpetrated by their husband; husband-wife communication on sexual and reproductive matters was limited; and several girls who had desired to delay their first pregnancy faced objections to contraception from their husband. Efforts are needed to encourage couple communication on sensitive issues (contraception, for example), negotiation, and conflict management skills early in the marriage. Efforts are also needed to inform married girls of their rights so that they have the opportunity to exercise control over their own lives; at the same time, efforts must be made to promote new concepts of masculinity and femininity and egalitarian couple relations among adolescents and youth. The gender transformative life skills education discussed earlier provides an important platform through which these norm changes may be encouraged. At the same time, efforts to reach newly married young couples with counselling, information, and opportunities for interaction would go a long way in enabling equitable marital relations.

\subsection{Support adolescents to exercise reproductive choices and receive continuum of care}

Our findings indicate that not all RMNCH+A (reproductive, maternal, newborn, child and adolescent health) programme services reach married adolescents. Programmes are needed, for example, that reach newly married girls and their husbands to inform them about their pregnancy postponement options and enable them to access 
appropriate contraception before pregnancy takes place. Concomitantly, providers, including such outreach workers as ASHAs, need to be trained and charged with the responsibility of ensuring that married adolescents who have not yet experienced pregnancy receive information on contraception and other reproductive health matters and are also given contraceptive supplies. The misconception held by healthcare providers that married adolescents will not seek contraception until they have experienced one pregnancy need to be changed. Similarly, the duties of healthcare providers towards those who have experienced pregnancy are to ensure that they receive information on the importance of seeking continuum of care. Many married girls lack the freedom of movement to seek healthcare, which demonstrates the need for health workers to reach these girls-particularly those newly married and first time pregnant-in their homes.

\section{Create awareness of citizenship responsbilities}

Findings have shown that fewer than half of all eligible adolescents had exercised their right to vote in the most recent elections preceding the survey. Prosocial attitudes were far from universal, with one third to one-half of adolescents reporting that they would not eat with a person of a different caste or religion, and between one-quarter and half justifying their right to retaliate with violence if disrespect was shown to a female family member or the respondent's religion. Inculcating citizenship values and practices from an early age are necessary for adolescents to develop civic consciousness and equitable attitudes.

\subsection{Promote active participation of adolescents in political processes and inculcate prosocial values}

Our survey findings demonstrate that programmes are needed at the school, college, and community level that encourage political participation, incorporate value-building components, and reinforce prosocial attitudes and values that espouse responsible citizenship. These can be introduced through the participation of adolescents in national service programmes, sports, and other non-formal mechanisms. Educational institutions, locally elected representatives and communities should provide opportunities to foster interaction between adolescents of different castes and religions. Findings also emphasise that the political system in the country needs to make special efforts to address the disillusionment of many adolescents about political matters and encourage their participation in the political processes in more meaningful ways.

\section{Realise the potential of the mass media and new technologies to reach adolescents with new ideas and opportunities}

We observed from our study that multiple media channels have a wide reach among adolescents, which suggests that the media can play a powerful role in conveying new ideas and pertinent information in the health, skilling, and employment realms to adolescents.

\subsection{Leverage adolescents' access to mass media, social media, and mobile phones to impart beneficial information}

We observed that large proportions of adolescents access the media-radio (16-33\%), television (73-90\%), and films ( $77-92 \%)$. They also have access to mobile phones (61-94\%), the internet and social media (17-42\% of boys and $(5-12 \%)$. The media can play an important role in enhancing their awareness of health-promoting behaviours and their entitlements, promoting supportive norms with regard to secondary school completion, inculcating positive notions of masculinity and femininity, and encouraging the adoption of healthy behaviours. Information about skilltraining programmes and employment opportunities may also be accessed through the media. Greater use of IVRS (interactive voice response) may offer opportunities to share health-promoting information with adolescents. Efforts are required to evaluate existing media and mobile-phone-based interventions for adolescents to assess their reach and impact in raising adolescents' awareness and enabling them to make informed choices. Efforts to employ the internet and social media to advance positive messaging to adolescents must take note of the wide gender discrepancies in access and ensure the continuation of more traditional modes of information provision for girls. 
Study findings indicate that parents and families play an enormous decision-making role in the life of their children, particularly in their daughters' lives. Notable proportions of boys and girls acknowledged gender discriminatory practices in their home, and many adolescents reported that their family life was marked by violence, both witnessed and experienced. They also reported that communication with parents on issues relevant to adolescents-such as school performance, friendship, experiences of being teased or bullied, physical changes during adolescence, and reproductive processes-was limited. At the same time, leading individuals from whom all adolescents learnt social behaviours were their parents, and of those adolescents who reported a role model, the majority reported someone from their family as their role model. In short, key life choices of adolescents are shaped by their parents, and, hence, programmes are needed that address parental mind sets, socialisation practices, and aspirations for sons and daughters.

\subsection{Create a supportive family environment}

Findings from UDAYA call for the introduction of programmes that focus on changing traditional socialisation patterns among parents. These programmes need to raise parental awareness of girls' abilities, opportunities, and rights; enable parents to reduce inhibitions about communicating with their adolescent children, including on such sensitive issues as harassment, violence, and sexual matters; and persuade them to make efforts to treat daughters and sons equally in giving them rights and responsibilities within the family, opportunities for education and vocational skill development, and access to money. Familiarising parents about the negative impact of intergenerational transmission of norms relating to the acceptability of violence and encouraging them to socialise their children to reject violence against women and girls are steps that would help to create positive attitudes and behaviours in their children during adolescence and in adulthood.

While evidence on models that are effective in bridging the distance between parents and their adolescent children or that enable parents to adopt more gender egalitarian socialisation practices is currently limited in India. A pilot study in rural Bihar had disappointing results, and it showed that there were very few changes in awareness, attitudes, and socialisation and communication practices that were attributable to participation in an intervention designed to sensitise parents on these issues (Jejeebhoy et al., 2014). There is a need to develop and pilot test new models that are both effective for and acceptable to parents.

Instead of a dedicated parenting programme, a possible alternative way to reach parents is through existing platforms-unrelated to parenting - that attract fathers or mothers of adolescents. For example, sessions on parenting may be folded into the sessions of self-help group meetings for women or in livelihood-training activities in which men and women participate; messages may be delivered to parents through mobile phones as well.

While parents of boys and girls in adolescent ages may be the most in need of exposure to new parenting skills, intervening with parents of younger children is likely to have more strategic impact, since it would prepare them to build closer relationships, foster more effective communication with children, and provide constructive support to children as they transition into adolescent and then adult roles. Presenting role models, that is, parents who have deviated from traditional norms and have communicated openly with their sons and daughters, may be an effective confidence-building measure for parents who hold more traditional views. This would reassure them that close parent-child relations and open communication about sexual and reproductive health matters would not lead boys and girls astray, and, on the contrary, would demonstrate that children of progressive parents had made successful transitions into higher education, employment, and positions of leadership. Efforts to solicit the support of community influentials and local leadership and hold community-level behaviour change communication events may be needed in order to enable parents of adolescent children to gain confidence about engaging in new practices.

Parents have also been identified as a preferred source of information, especially by girls; yet very few reported actually receiving any information related to reproductive processes from a parent. Also needed, therefore, are efforts to engage parents by providing them with accurate information and working with them to overcome inhibitions about imparting information to their children, particularly to their daughters. 


\section{Remove hindrances to awareness and use of entitlements}

Although the government has provided a large number of entitlements and services that can have a direct impact on adolescent well-being, few adolescents are aware of many of these entitlements and services, and bottlenecks have hampered the reach of these entitlements and services. In many instances, the most vulnerable and needy adolescents, such as the poorest, those from socially disadvantaged communities, and those whose parents are uneducated are excluded from the ambit of these services. Programmes need to explore ways of overcoming obstacles in accessing entitlements and services.

\subsection{Revamp adolescent programmes}

The reach of programmes intended to meet the development and health needs of adolescents remains strikingly limited in the state. While schemes to promote school completion, such as the provision of midday meals, free textbooks and uniforms, and scholarships, are widely known, their reach is far from satisfactory. Programmes to promote skill-building and employment generation, programmmes to impart health information to adolescents and to meet their health needs, such as the health programmes in schools and colleges, adolescent friendly health clinics, sanitary napkins distribution scheme, and the family life education programme are less known and their reach is limited. These findings call for efforts to build awareness among adolescents and their gatekeepers about the availability of these entitlements through better branding of these schemes, on the one hand, and improved delivery of programmes and stronger linkages across programmes, on the other.

\section{Ensure inclusion of the most vulnerable}

While almost all adolescents are in need of the benefits of the many programmes and entitlements available to them, ensuring that the most vulnerable groups of adolescents are not left out is imperative. Our findings highlight that married adolescent girls, those who had never been to school or had discontinued schooling, those with poorly educated mothers, and those who belonged to socio-economically vulnerable groups consistently scored poorly on markers of successful transitions to adulthood. These findings, therefore, call for special attention and strategic investment in these vulnerable groups. Finally, our findings indicate that vulnerabilities are manifested in early adolescence and, hence, investments starting in early adolescence or even earlier are crucial for the development of adolescents. 


\section{References}

Acharya, R., S. Kalyanwala, and S. J. Jejeebhoy. 2009. Broadening Girls' Horizons: Effects of a Life Skills Education Programme in Rural Uttar Pradesh. New Delhi: Population Council.

Achyut, P., N. Bhatla, S. Khandekar, et al. 2011. Building Support for Gender Equality among Young Adolescents in School: Findings from Mumbai, India. New Delhi: ICRW.

Balaji, M., T. Andrews, G. Andrew, et al. 2011. "The acceptability, feasibility, and effectiveness of a population based intervention to promote youth health: An exploratory study in Goa, India," Journal of Adolescent health 48(5): 453-60.

Banerjee, A., S. Cole, E. Duflo et al. 2007. "Remedying education: Evidence from two randomized experiments in India," The Quarterly Journal of Economics 122(3): 1235-64.

Banerjee, A., R. Banerji, J. Berry et al. 2016. Mainstreaming an effective intervention: Evidence from randomized evaluations of "Teaching at the Right Level" in India. National Bureau of Economic Research (NBER), Working Paper No. 22746. Accessed on 11 August 2017 at http://www.nber.org/papers/w22746.pdf.

Centre for Development and Population Activities (CEDPA). 2006. Empowering Adolescents in India: The Better Life Options Program. Accessed on 1 November 2017 at https://www.popline.org/node/191418.

Chin, A. 2005. "Can redistributing teachers across schools raise educational attainment? Evidence from operation black-board in India," Journal of Development Economics 78(2): 384-405.

Clarke, A. M., T. Kuosmanen and M. M. Barry. 2015. "A systematic review of online youth mental health promotion and prevention interventions," Journal of Youth and Adolescence 44(1): 90-113.

Das, M., S. Ghosh, E. Miller et al. 2012. Engaging Coaches and Athletes in Fostering Gender Equity: Findings from the Parivartan Program in Mumbai, India. New Delhi: ICRW \& Futures Without Violence.

International Institute for Population Sciences. 2017. National Family Health Survey, State Factsheet Uttar Pradesh 2015-2016 (NFHS-4). Accessed on 17 April 2017 at http://rchiips.org/nfhs/pdf/NFHS4/UP_FactSheet.pdf.

Jejeebhoy. S. J., A. J. F. Zavier, K. G. Santhya et al., 2014. Promoting Parent-Child Interaction and Communication for Healthy Development of Adolescents: Lessons from a Pilot Project in Rural Bihar. New Delhi: Population Council.

Jejeebhoy, S. J. 2017. Supporting Transitions from Adolescence to Adulthood: Evidence-informed Leads for Investment. New Delhi: Bill and Melinda Gates Foundation.

Jejeebhoy, S. J., R. Acharya, N. Pandey et al. 2017a. The Effect of a Gender Transformative Life Skills Education and Sports-Coaching Programme on the Attitudes and Practices of Adolescent Boys and Young Men in Bihar. New Delhi: Population Council.

Jejeebhoy, S. J., K. G. Santhya, S. Singh et al. 2017b. Feasibility of Screening and Referring Women Experiencing Marital Violence by Engaging Frontline Workers: Evidence from Rural Bihar. New Delhi: Population Council.

Lakshminarayana, R., A. Eble, P. Bhakta et al. 2013. "The support to rural India's public education system (STRIPES) trial: A cluster randomised controlled trial of supplementary teaching, learning material and material support," PLoS One 8 (7): e65775.

Linden, L. 2008. “Complement or substitute? The effect of technology on student achievement in India," J-PAL Working paper. Accessed on 11 August 2017 at https://www.povertyactionlab.org/evaluation/complement-orsubstitute-effect-technology-student-achievement-india.

Mehra, S., R. R. Singh, V. Nair, et.al. 2016. Addressing Adolescent Girls' Vulnerability to HIV/AIDS: Lessons from the Meri Life Meri Choice project. New Delhi: Population Council.

Ministry of Health and Family Welfare. 2017. National Health Policy 2017. New Delhi: Ministry of Health and Family Welfare, Government of India. 
Ministry of Human Resource Development (MOHRD). 2016. Some inputs for Draft National Education policy. New Delhi: Ministry of Human Resource Development, Government of India. Accessed on 29 June 2017 at http://mhrd. gov.in/sites/upload_files/mhrd/files/document-reports/NPE86-mod92.pdf.

Ministry of Human Resource Development (MOHRD). 2017a. New measures to assess learning outcomes. New Delhi: Ministry of Human Resource Development, Government of India. Accessed on 10 August 2017 at http://mhrd.gov.in/ new-measures-assess-learning-outcomes.

Ministry of Human Resource Development (MOHRD). 2017b. Quality education in government schools. New Delhi: Ministry of Human Resource Development, Government of India. Accessed on 10 August 2017 at http://mhrd.gov.in/ quality-education-government-schools.

Ministry of Skill Development and Entrepreneurship. 2015. National Policy for Skill Development and Entrepreneurship. New Delhi: Ministry of Skill Development and Entrepreneurship, Government of India.

Muralidharan, K. and N. Prakash. 2017. "Cycling to school: Increasing secondary school enrollment for girls in India," American Economic Journal: Applied Economics 9(3): 321-50.

Muralidharan, K. and V. Sundararaman. 2011. "Teacher performance pay: Experimental evidence from India," Journal of Political Economy 119(1): 39-77.

Muralidharan, K. and V. Sundararaman. 2013. "Contract teachers: Experimental evidence from India," National Bureau of Economic Research (NBER), Working paper 19440. Accessed on 11 August 2017 at http://www.nber.org/ papers/w19440.

Nanda, P., P. Das, N. Datta, et al. 2016. "Making change with cash? Impact of a conditional cash transfer program on girls' education in India," in Impact on Marriage: Program Assessment of Conditional Cash Transfers. Washington DC: ICRW

Pandey, N., S. J. Jejeebhoy, R. Acharya et al. 2016. Effects of the PRACHAR Project's Reproductive Health Training Programme for Adolescents: Findings from a Longitudinal Study. New Delhi: Population Council.

Patel, V., H. A. Weiss, N. Chowdhary et al. 2010. "Effectiveness of an intervention led by lay health counsellors for depressive and anxiety disorders in primary care in Goa, India (MANAS): A cluster randomised controlled trial," The Lancet 376(9758): 2086-95.

Rajaraman, D., S. Travasso, A. Chatterjee, et al. 2012. "The acceptability, feasibility and impact of a lay health counsellor delivered health promoting schools programme in India: A case study evaluation," BMC Health Services Research 12:127.

Santhya, K. G., A. J. Francis Zavier, P. Patel et al. 2016. Engaging Parents to Promote Girls' Transition to Secondary Education: Evidence from a Cluster Randomised Trial in Rural Gujarat, India. New Delhi: Population Council.

Sekher, T.V. and F. Ram. 2015. Conditional Cash Transfers for Girls in India: Assessment of a Girl Child Promotion Scheme from Beneficiary Perspective. Mumbai: International Institute for Population Sciences (IIPS).

Srikala, B and Kishore Kumar K. V. 2010. "Empowering adolescents with life skills education in schools - School mental health program: Does it work?," Indian Journal of Psychiatry 52(4): 344-49.

United Nations Population Fund (UNFPA). 2014. Action for Adolescent Girls. New York: UNFPA.

Verma, R. K., J. Pulerwitz, V. Mahendra, et al. 2006. "Challenging and changing gender attitudes among young men in India," Reproductive Health Matters 14(28): 135-43.

World Health Organization. 2010. Violence Prevention the Evidence: Series of Briefings on Violence Prevention. Geneva: World Health Organization. 
Designed by: Mensa Design Private Limited and Auriga Consultancy and Management Services.

Printed by: Mensa Design Private Limited - design.mensa@gmail.com 


\section{Study supported by:}

\section{BILL\&MELINDA \\ GATES foundation \\ the David \\ Lucile Packard FOUNDATION}

